\title{
Review
}

\section{Sphingolipid transport in eukaryotic cells}

\author{
Gerrit van Meer*, Joost C.M. Holthuis \\ Department of Cell Biology and Histology, Academic Medical Center, University of Amsterdam, P.O. Box 22700, 1100 DE Amsterdam, \\ The Netherlands
}

Received 27 October 1999; received in revised form 9 November 1999; accepted 9 November 1999

\begin{abstract}
Sphingolipids constitute a sizeable fraction of the membrane lipids in all eukaryotes and are indispensable for eukaryotic life. First of all, the involvement of sphingolipids in organizing the lateral domain structure of membranes appears essential for processes like protein sorting and membrane signaling. In addition, recognition events between complex glycosphingolipids and glycoproteins are thought to be required for tissue differentiation in higher eukaryotes and for other specific cell interactions. Finally, upon certain stimuli like stress or receptor activation, sphingolipids give rise to a variety of second messengers with effects on cellular homeostasis. All sphingolipid actions are governed by their local concentration. The intricate control of their intracellular topology by the proteins responsible for their synthesis, hydrolysis and intracellular transport is the topic of this review. (C) 2000 Elsevier Science B.V. All rights reserved.
\end{abstract}

Keywords: Sphingomyelin; Inositolsphingolipid; Glycosphingolipid; Glycolipid; Translocation; Animal cell; Yeast

\section{Introduction}

Eukaryotic cells contain multiple membranebound compartments whose specialized functions require distinct protein and lipid compositions. Assembly of the correct mixture of proteins and lipids into each compartment requires a three-step process in-

\footnotetext{
Abbreviations: Cer, ceramide; CGlcT, ceramide glucosyltransferase; GalCer, galactosylceramide; GalNAc, $N$-acetylgalactosamine; GlcCer, glucosylceramide; GPI, glycosylphosphatidylinositol; IPC, inositolphosphoceramide; MIPC, mannosylinositolphosphoceramide; $\mathrm{M}(\mathrm{IP})_{2} \mathrm{C}$, inositolphospho-mannosylinositolphosphoceramide; SM, sphingomyelin; TGN, trans-Golgi network; Glycosphingolipid designation according to the recommendations of the IUPAC-IUB Joint Commission on Biochemical Nomenclature [1], using the Svennerholm abbreviations for gangliosides and using sulfatide to indicate $\mathrm{HSO}_{3}-3 \mathrm{Gal} \beta 1-1 \mathrm{Cer}$

* Corresponding author. Fax: +31-20-6974156;

E-mail: g.vanmeer@amc.uva.nl
}

volving (1) the biosynthesis of proteins and lipids, (2) selective transport of proteins and lipids across the compartmental bilayer (intracompartmental transport), and (3) selective transport of proteins and lipids between different compartments (intercompartmental transport; see Fig. 1). Experimental work over the last 15 years has brought us detailed knowledge concerning the molecular mechanisms responsible for intra- and intercompartmental protein transport. In contrast, our insight into how lipids are sorted and moved within cells is far more limited. This is partially due to the fact that the trafficking rules that apply to lipids are less absolute than those for proteins, and therefore more difficult to translate into molecular terms. On the other hand, it is becoming increasingly clear that directional transport of at least some protein and lipid species is controlled by intricate sorting machineries. A striking example are the sphingolipid-cholesterol microdomains, called 


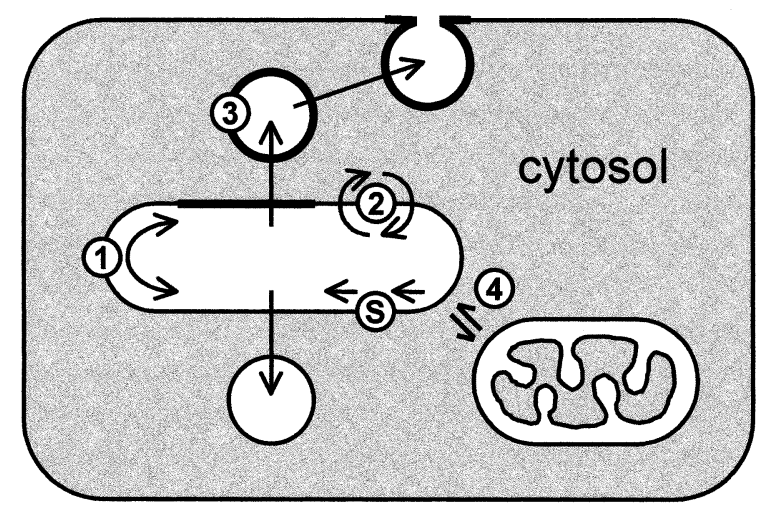

Fig. 1. Mechanisms of lipid transport. Membrane lipids diffuse laterally (lateral diffusion: 1) and transversely (transbilayer translocation: 2) in the membrane of each compartment, in this case for example the TGN (S: synthesis). Since lipids form the membrane matrix they are an integral part of vesicular carriers (vesicular traffic: 3) to, for example, the plasma membrane. Sorting along this pathway involves local changes in surface density at the sites of vesicle budding. At the same time, lipid molecules may exchange as monomers between the cytosolic membrane surfaces of all cellular compartments (monomeric transfer: 4). The latter process is especially relevant for organelles that are not connected by vesicular traffic like mitochondria and peroxisomes. Processes 1 and 2 are intracompartmental, 3 and 4 intercompartmental. The differences in lipid composition between organelles and between the two bilayer leaflets require specificity in the various transport processes. The question is, what molecular interactions are responsible for the specificity?

rafts, that have initially been proposed to function as sorting devices for protein and lipid transport from the Golgi to the apical cell surface in polarized epithelial cells [2]. Since then, an increasing number of cell biological and biochemical studies has indicated that rafts (1) are not only employed by polarizedepithelial cells, but also by many other cell types, including lower eukaryotes such as yeast, (2) occur at diverse intracellular locations and (3) play a role in cellular processes other than membrane trafficking alone. For example, at the plasma membrane their presence has important functional consequences for the activation of signaling cascades (reviewed in [35]). At the basis of raft formation lies the intrinsic tendency of sphingolipids to cluster with cholesterol in the plane of the membrane. Further progress in our understanding of raft dynamics and function in cells will therefore critically depend on our knowledge concerning the characteristics of its most elementary components, the sphingolipids.
Sphingolipids, comprising all lipids carrying a long-chain sphingoid base as their structural backbone (Fig. 2), are essential for eukaryotic life under natural conditions [6-8]. Although their roles in membrane structure and organization have been appreciated for some time, members of this diverse group of lipids are now also emerging as a novel class of signaling molecules that affect important cellular processes such as cell growth and survival (reviewed in [9-11]). How this multitude of actions comes into existence is poorly understood, but obviously depends on the type of headgroup and fatty chains of each particular sphingolipid involved. As sphingolipids are enriched in the outer leaflet of plasma membranes, but fulfill functions at a number of other locations in the cell as well, it will be important to determine how the appropriate distribution of sphingolipids over the various subcellular membrane surfaces is maintained. For this, it will be necessary to define the cellular sites of sphingolipid synthesis and hydrolysis. Also, it is necessary to determine the quantitative contributions of the various pathways of sphingolipid transport and the mechanisms that are responsible for the specificity in these pathways towards sphingolipids. Finally, in order to map the cellular sphingolipid economy, it is relevant to find out how synthesis, hydrolysis and transport along the various pathways are coordinately regulated in time and under different physiological conditions. Here, we explore what has been learned to date with respect to the issues raised above, and try to get a feeling for how sphingolipid metabolism and organization are integrated in eukaryotic life.

\section{Possible mechanisms of intracellular sphingolipid transport}

Because of their hydrophobic chain(s), sphingolipids are part of the lipid matrix of membranes. They rapidly diffuse in membranes with diffusion coefficients that are 10-100-fold larger than those of most membrane proteins: $10^{-8}-10^{-9} \mathrm{~cm}^{2} / \mathrm{s}$, which means that they cover an area of $0.1-1 \mu \mathrm{m}^{2} / \mathrm{s}$ in a cell of typically $10-20 \mu \mathrm{m}$ in each dimension (intracompartmental; Fig. 1:1). They will thus participate in vesicular membrane traffic (intercompartmental; Fig. 1: 3). Since sphingolipids are synthesized in 
A.

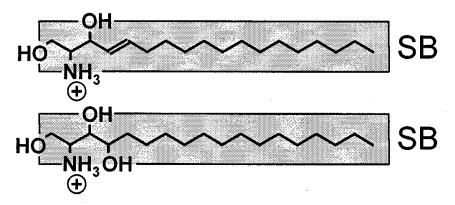

B.

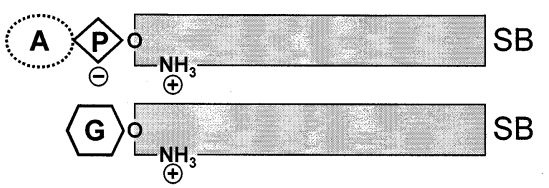

C.

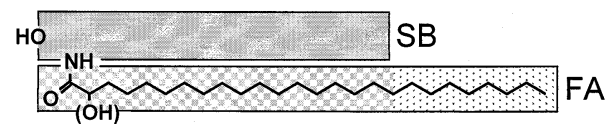

D.
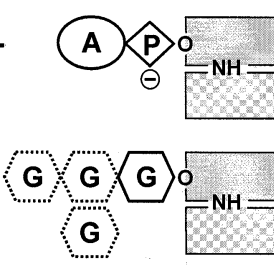

Fig. 2. Schematic structure of sphingolipids. All sphingolipids contain a sphingoid base, SB, an amino alcohol of typically 1820 carbon atoms, as their basic structural motif (A). The saturated $\mathrm{C}_{18}$ form is referred to as sphinganine, the form with a double bond between $\mathrm{C}_{4}$ and $\mathrm{C}_{5}$ as sphingosine, and the saturated form with an additional hydroxyl at $\mathrm{C}_{4}$ as phytosphingosine [1]. The sphingoid base may contain a polar headgroup, as in sphingosine-1-phosphate (B), or in lysosphingolipids where A represents choline or inositol, and $\mathrm{G}$ a carbohydrate such as glucose in the case of glucopsychosine. When $N$-acylated with a fatty acid, FA, with a typical length of 18-26 carbons, the molecule is termed ceramide (Cer; C). Some, but not all, fatty acid adducts are hydroxylated as in (C). The bulk of the cellular sphingolipids contains a polar headgroup (D). In mammals the headgroup is phosphocholine in sphingomyelin (SM), and a carbohydrate in glycosphingolipids. The carbohydrate can be glucose in glucosylceramide (GlcCer), galactose in galactosylceramide (GalCer), or may be complex, mostly based on glucose. In plants and yeast, the headgroup is phosphoinositol (inositolphosphoceramide, IPC), often glycosylated and otherwise extended, which in yeast results in mannosyl-inositolphosphoceramide (MIPC), and inositolphosphomannosyl-inositolphosphoceramide $\left(\mathrm{M}(\mathrm{IP})_{2} \mathrm{C}\right)$. However, a multitude of other headgroups have been identified in the various eukaryotes and even in some bacteria $[79,156]$

the endoplasmic reticulum (ER) and the Golgi but are enriched in the plasma membrane, they must be subject to extensive intracellular sorting. Since sphingolipid sorting and protein sorting coevolved in evo- lution, their sorting may occur at the same sites, and the mechanisms by which proteins and sphingolipids are segregated may be interdependent. In both cases sorting of the molecule involves a local change in its surface density at a site of vesicle budding.

Major sites for protein sorting are situated at the exit sites of the organelles lining the secretory pathway and the endocytotic recycling pathway. In the $\mathrm{ER}$, proteins are sorted at the transitional elements [12-15]. In the Golgi, protein sorting occurs at the cis-exit back to the ER [12], at the rims of each cisterna [16-20], and at the trans-Golgi network (TGN) back into the Golgi stack, to the plasma membrane (domains in epithelial cells), to secretory granules, and to the elements of the endocytotic pathway [21-24]. Proteins are sorted into various endocytotic pathways to the endosomes [25], and, in the endosomes, back to the plasma membrane, to the TGN, and to later compartments in the pathway like lysosomes in mammals and the vacuole in yeast [26,27].

Membrane lipids only span half the membrane and they are much smaller than proteins. For that reason, various possibilities must be considered for lipid transport that are generally irrelevant for membrane proteins. First of all, lipids can move between the two monolayers of the membrane lipid bilayer, a process termed transbilayer translocation or flipflop, where 'flip' has been coined for the translocation towards the cytosolic membrane leaflet (Fig. 1: 2). In model lipid membranes this process is generally slow for the lipids that carry a polar headgroup (Fig. 2B,D) but more rapid for lipids without one (Fig. 2A,C). In cells, the process may be facilitated or even driven by proteins termed flippases or translocators. A second mechanism of transport that is mostly irrelevant in the case of membrane proteins is desorption of the lipid from the membrane into the aqueous phase and insertion into a different membrane (Fig. 1: 4). This process is slow for the sphingolipids carrying two long fatty chains (Fig. 2C,D) but relatively rapid for single chain sphingolipids (Fig. 2A,B, or sphingolipids carrying short acyl chains like C6, see Section 5.2). Monomeric exchange can be facilitated by soluble lipid transfer proteins, or by the existence of close contacts between membranes, like those between ER and mitochondria [2831]. Monomeric exchange as a transport mechanism 
is only relevant between cytosolic membrane leaflets. So far, there is no evidence that compartments exchange lipids via hemi-fusion, whereby lipids would diffuse from the one compartment to the other via a continuous cytosolic membrane leaflet.

\section{The subcellular distribution of sphingolipids}

\subsection{Sphingomyelin}

Most data on the distribution of sphingolipids over the various cellular organelles have been derived from cell fractionation studies on rat liver. These have been mostly limited to the phosphosphingolipid sphingomyelin (SM), by far the most abundant sphingolipid in this tissue. Generally, SM was found enriched in the plasma membrane as compared to the ER with an intermediate concentration in the Golgi. Whereas the SM concentration as a percentage of total phospholipid was $2-4 \%$ in the ER, it was found to be $15-23 \%$ in the plasma membrane [32-35]. Mitochondria were found to contain 1-2\% SM [33,34]. Lysosomes were found to contain amounts similar to or higher than plasma membranes $[33,36]$. Unfortunately, the values reported in the earlier studies cannot be taken too absolutely, as endosomes were not recognized as discrete membranes until the early 1980s, and thus contaminated the isolated organelles. Endosomes were found to contain SM concentrations at least as high as found in plasma membranes [37,38]. A loss of the distinct SM distribution over the various organelles has been reported for fetal liver and fast-growing hepatomas. Under neoplastic conditions, a remarkable increase was observed in the SM concentration of the mitochondria [39-42].

Unusually high concentrations of SM have been reported for the apical plasma membrane domain of epithelial cells isolated from the kidney cortex of rats and dogs. While the basolateral phospholipids contained $19 \% \mathrm{SM}$, this was $36 \%$ for the apical domain [43-46]. "Percent of phospholipid" is not a direct reflection of the concentration or surface density of the lipid in the membrane since this term does not take into account the presence of non-phosphate containing lipids like cholesterol and glycosphingolipids [47]. However, the glycosphingolipid content of brush border from rat renal cortex is very low $(4 \mu \mathrm{g} /$ mg protein [48]) as compared to apical membranes from intestinal cells $(300 \mu \mathrm{g} / \mathrm{mg}$ protein $[49,50])$, which contain equimolar amounts of glycosphingolipids, phospholipids, and cholesterol.

The distribution of SM across the plasma membrane was first addressed by the application of exogenous bacterial sphingomyelinase to erythrocytes [51]. According to this assay, $80-85 \%$ of the SM resided in the external, non-cytosolic leaflet of the bilayer. Similar data obtained on a membrane virus that budded from the plasma membrane of BHK cells and on isolated plasma membrane vesicles have been interpreted as an indication that SM is highly enriched in the non-cytosolic plasma membrane leaflet of nucleated cells [52-54]. Sphingomyelinase has also been applied directly to nucleated cells, mostly in the context of lipid transport studies (see Section 6.1). In some cases, plasma membranes were isolated from the treated cells to allow for a calculation of lipid asymmetry, which in all cases assigned most SM to the non-cytosolic surface [5557]. In line with this, sphingomyelinase assigned $80 \%$ of the SM to the lumenal, non-cytosolic surface of chromaffin granules [58]. Some forms of cellular signaling involve hydrolysis of SM by an endogenous neutral sphingomyelinase $[9,59,60]$. The enzyme [60] probably resides on the cytosolic surface of the plasma membrane. Evidence, partially obtained using exogenous sphingomyelinase, has assigned the 'signaling' SM pool to the cytosolic leaflet of the plasma membrane [61-63].

In erythrocyte membranes, the sphingomyelinaseresistant SM pool contained shorter fatty acids [64]. This could imply that the inner leaflet SM contains shorter fatty acids. Alternatively, all SM could be accessible to the sphingomyelinase, the enzyme action could be incomplete (as reported for other phospholipases C, see [65]), and it could display a preference for long-chain SM. Actually, some observations suggest that the sphingomyelinase assay may not be generally applicable. Sphingomyelinase treatment of isolated intestinal brush border membranes yielded higher values for the accessible SM than did an assay based on a lipid transfer protein [66]. In addition, the sphingomyelinase assay applied to a membrane virus [53] yielded higher values that the original study on the lipid asymmetry of BHK cell-derived virus, which used a kinetic assessment of the SM hydrolysis [67]. 
The possibility exists that the conversion of the bilayer-forming SM to the non-bilayer-forming ceramide (Cer) may disrupt the transbilayer orientation of the lipids when the fraction of SM in the leaflet that is accessible to the sphingomyelinase is too high [68], as has been found to be the case for phospholipases C $[65,69]$.

Of the cellular SM, 90\% has been assigned to the plasma membrane in human fibroblasts [70]. This estimation seems high in the light of stereometric measurements which indicated that the surface ratio of endocytotic membranes/plasma membrane is 0.25 in fibroblastic BHK cells [71]. These membranes contain similar concentrations of SM [37,38]. Sphingomyelinase generally hydrolyzes some $60-65 \%$ of the total cellular SM when applied at $37^{\circ} \mathrm{C}$ for $1 \mathrm{~h}$. Glutaraldehyde fixation did not change this number suggesting that replenishment of the surface SM by recycling SM did not occur under sphingomyelinase conditions [72]. The fact that similar numbers were obtained when sphingomyelinase was applied at the reduced temperature of $15^{\circ} \mathrm{C}$, where vesicular traffic is essentially blocked, confirms that most of the cellular SM is situated in the plasma membrane [73,74]. Notably, signaling events that involve endogenous hydrolysis of SM will, locally and temporarily, reduce the concentration of SM.

SM is constitutively degraded in the lysosomes. SM accumulates in the lysosomes when the acid sphingomyelinase is inhibited, as in patients suffering from Niemann-Pick disease type A and B which are due to mutations in the acid sphingomyelinase [75,76]. Interestingly, Niemann-Pick type $\mathrm{C}$ disease is characterized by accumulation of SM but the actual defect is in intracellular cholesterol transport [77,78].

\subsection{Inositolsphingolipids}

Instead of SM, a large number of eukaryotic organisms (including plants, fungi and protozoa) contain inositolphosphoceramide (IPC) and its more complex, glycosylated derivatives [79]. In yeast, where this class of sphingolipids has been subject to extensive investigations, three major species are found: IPC, mannosyl-IPC (MIPC), and inositolphospho-mannosyl-IPC $\left(\mathrm{M}(\mathrm{IP})_{2} \mathrm{C}\right) . \quad \mathrm{M}(\mathrm{IP})_{2} \mathrm{C}$, the most complex sphingolipid found in yeast, accounts for $75 \%$ of the mass of total sphingolipids [80]. IPC, MIPC and $\mathrm{M}(\mathrm{IP})_{2} \mathrm{C}$ are primarily located in the yeast plasma membrane, where they constitute some $30 \%$ of total phospholipid [81]. Upon closer inspection [82], considerable amounts of IPC were found both in the Golgi and in the vacuole (the yeast equivalent of lysosomes). Trace amounts of IPC were found in mitochondria but none has been detected in lipid particles. Nuclei were not examined. No data are available on the distribution of the IPCs over the two leaflets of the plasma membrane bilayer. Interestingly, in yeast the glycosylphosphatidylinositol anchor by which some proteins (GPI proteins) are attached to the non-cytosolic leaflet of secretory membranes is modified by the replacement of the diacylglycerol by Cer [83]. This remodeling is carried out by an as yet unidentified enzyme(s) which resides in the ER and the Golgi [84].

\subsection{Glycosphingolipids}

Glycosphingolipids have been found to be exposed on the cell surface by a number of techniques. Galactose lipids were assayed by chemical oxidation using periodate [85], and by enzymatic oxidation using galactose oxidase [86-89]. The presence of ganglioside neuraminic acid on the cell surface was addressed using periodate oxidation [90-92] and by exogenously added neuraminidase [90,93,94]. The presence of numerous different glycosphingolipids on cell surfaces has been demonstrated using binding proteins that express preferential binding to specific glycosphingolipids. Examples are antibodies, toxins, and lectins. The general picture from this work is that the majority of the glycosphingolipids is situated in the plasma membrane and is facing outwards (reviewed in [68]). Whereas glycosphingolipids usually constitute a minor fraction of the plasma membrane lipids (several $\mathrm{mol} \%$ of total lipid), particularly high concentrations of glycosphingolipids have been reported for the apical plasma membrane domain of epithelial cells from intestine $[49,50,95]$ and urinary bladder [96], which contained double the glycosphingolipid concentration (30-40 $\mathrm{mol} \%$ of total lipid) of the basolateral surface domain.

It is known that intracellular pools of glycosphingolipids exist in glycosphingolipid storage diseases (see [75]), and that glucosylceramide (GlcCer) is 
stored in lamellar bodies in keratinocytes as a precursor for extracellular skin Cers [97,98], but it has become clear that intracellular pools of sphingolipids are a more general phenomenon [99-102]. Sphingolipids have been colocalized with cytoskeletal elements using fluorescence microscopy, but the necessity of using detergent has complicated the interpretations [103-106]. A major technical improvement was the application of the freeze-substitution technology to the immuno-gold electron microscopic (EM) localization of glycosphingolipids. Forssman glycolipid, $\mathrm{IV}^{3}-\alpha-N$-acetylgalactosamine (GalNAc)-Gb ${ }_{4} \mathrm{Cer}$, was localized by an antibody to the plasma membrane but was found in high concentrations in endocytotic compartments [107]. While small but distinct concentrations of Forssman glycolipid were observed over the Golgi and the ER, no gold label was observed over mitochondria and peroxisomes. As for SM, a highly increased content of the ganglioside GD1b was reported for the mitochondria of a malignant hepatoma [108]. It will be interesting to see a confirmation of these biochemical data by immuno-EM. By the same technique it was found that the ganglioside GM1, labeled by cholera toxin, was not distributed uniformly on the cell surface but was concentrated four-fold in caveolae [109].

From their presence on the cell surface, the noncytosolic leaflet of the plasma membrane, glycosphingolipids would be expected to reside on the lumenal surface of the compartments along the secretory and endocytotic pathways. However, newly synthesized GlcCer has been localized on the cytosolic surface of the Golgi [110]. In addition, proteins have been isolated from cytosol that can interact with (specific) glycosphingolipids (Section 6.2), which leaves open the possibility that a fraction of the glycosphingolipids is oriented towards the cytosol [111-114].

\subsection{Other sphingolipids}

Only few data are available on the intracellular distribution of sphingoid bases or their phosphorylated forms, and Cers. The Cer concentration was reported to be twice as high in plasma membrane as in the ER of rat liver [35], while $10-15 \%$ of the total Cer pool was estimated to reside in the plasma membrane of CHO cells [115]. Obviously, Cer is produced in the biosynthetic route, but also by hydroly- sis. Constitutive hydrolysis of SM, glycosphingolipids, and Cer occurs in the lysosomes. In the absence of acid ceramidase, Cer accumulates in the lysosomes (Farber disease; see [116,117]). Cer can also be produced during signal transduction via the SM cycle, or by the non-lysosomal glucosylceramidase, presumably at the plasma membrane (Section 4.1). Clearly, the relative amounts of Cer and SM in the signaling compartment will change when cell stimulation activates this pathway $[9,59]$.

\section{Topology of sphingolipid synthesis and hydrolysis}

\subsection{Sphingoid bases and ceramide}

The first committed step in sphingolipid synthesis is the condensation of palmitoyl-CoA and serine to 3-ketosphinganine [1]. This then acts as a precursor for the sphingolipids sphinganine and phytosphingosine $[118,119]$, both long-chain amino alcohols (Fig. 2). The sphingoid bases are converted to Cer by $N$ acylation. Only then the sphinganine chain can be desaturated to sphingosine $[120,121]$. Cellular sphingosine is therefore the product of hydrolysis of Cer or higher sphingolipids. In yeast (but to some extent also in mammals) sphinganine is hydroxylated to phytosphingosine before $N$-acylation. Cer assembly and the introductory reactions occur on the cytosolic surface of the ER (Fig. 3) [122]. Alternatively, Cer is produced from hydrolysis of SM and glycosphingolipids. Constitutive hydrolysis occurs in the lysosomes by acid sphingomyelinase and cerebrosidases. In addition, Cer is produced by a neutral sphingomyelinase, probably at the plasma membrane (see [60]), or by a non-lysosomal glucosylceramidase [123]. Cer itself is degraded in the lysosomes by an acid ceramidase $[124,125]$.

Sphingosine, phytosphingosine, and sphinganine can be phosphorylated [126-128]. The enzymes were found to be partially membrane-associated, although none of them contains a conserved membrane localization signal [128-131]. The phosphorylation serves as a first step in the degradative pathway. It is followed by the activity of a lyase on the cytosolic surface of the ER membrane which converts phosphorylated long-chain bases into ethanolamine phosphate and a fatty aldehyde [132-134]. In 


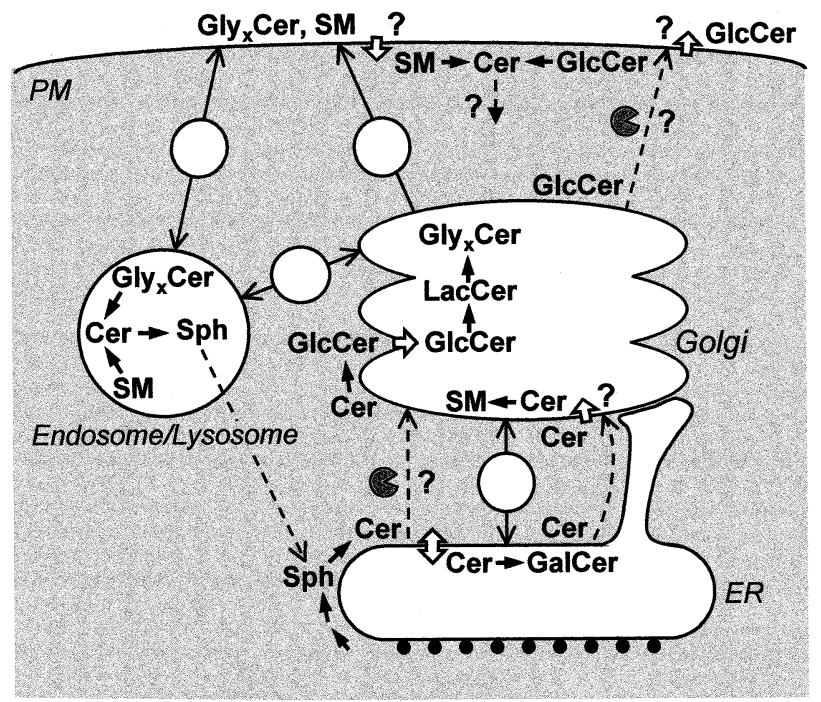

Fig. 3. Comprehensive view of intracellular sphingolipid transport. Sphinganine or phytosphingosine ( $\mathrm{Sph}$ ) in the ER is $\mathrm{N}$-acylated to ceramide (Cer). Cer is transported by vesicular traffic and/or an undefined non-vesicular pathway (?) to the cis-aspect of the Golgi, drawn here as a single compartment. Cer can cross the ER membrane and, in some cell types, be converted to GalCer. GalCer can then follow the vesicular pathways. On the cytosolic surface of the Golgi, Cer is converted to GlcCer. GlcCer, at least partially, translocates towards the lumenal leaflet of the Golgi membrane, where it can be galactosylated to LacCer and further glycosylated $\left(\mathrm{Gly}_{\mathrm{x}} \mathrm{Cer}\right)$. After translocation across the membrane of the ER or the Golgi, Cer on the lumenal side of the Golgi can be converted to SM. All lumenal lipids can follow the vesicular transport steps to the plasma membrane (PM) and into the endocytotic recycling pathway. During recycling small quantities of the sphingolipids end up in the lysosome (drawn here as part of the endosome), where they are degraded to Cer and (phyto)sphingosine ( $\mathrm{Sph}$ ). This base can diffuse as a monomer across the lysosomal membrane and the cytosol to the ER for reutilization. GlcCer on the cytosolic surface of the Golgi can be transported by vesicular or monomeric (protein-mediated?) transport to the cytosolic surface of the plasma membrane. There it can be translocated to the outer leaflet (by a multidrug transporter), or it can be degraded by the non-lysosomal glucosylceramidase. SM on the cell surface may be translocated inwards (by the scramblase?) and be degraded by the neutral sphingomyelinase. The fate of the resulting Cer is unclear. The preferential incorporation of sphingolipids in the vesicular pathway from ER and Golgi to the plasma membrane is not indicated. This preferential incorporation may be mediated by sphingolipid rafts on the lumenal surface, while anterograde transport of Cer and GlcCer may also be mediated by rafts on the cytosolic surface.

addition, the sphingoid base phosphates appear to be important signaling molecules (see $[11,135]$ ). The molecules can be inactivated by the lyase or by a specific phosphatase [136-139].

\subsection{Sphingomyelin}

In mammals, Cer can be converted to SM by the transfer of a phosphocholine moiety from phosphatidylcholine yielding SM plus diacylglycerol. The topology of this reaction, whether it occurs in the Golgi, on the plasma membrane, or in endosomes, has long been a matter of debate. This was partially due to the fact that these membranes could not be reliably separated in the initial studies. The present evidence suggests that Cer from the ER is transported to the Golgi and is converted to SM on the lumenal surface of the membrane of the cis- and medial Golgi ([140-142]; Fig. 3). In line with this, brefeldin A, a drug that makes the Golgi complex fuse with the ER [143], relocated SM synthase activity to the mixed ER-Golgi compartment in $\mathrm{CHO}$ cells [74]. However, no relocation was observed in hepatocyte-derived HepG2 cells [144], which may indicate that SM synthase in hepatocytes is situated in the trans-Golgi or TGN. This may also be the case in neurons, where SM synthesis was reduced by brefel$\operatorname{din}$ A [145].

At the same time, part of the SM synthase activity was assigned to the plasma membrane [140] and a SM synthase activity has been found on the surface of epithelial cells, where it is exclusively present on the basolateral surface [146]. This activity has now been observed on the surface of many cell types including polarized [147] and non-polarized cells $[74,148]$. In a direct experiment to settle an ongoing discussion [149] endosomes contained no sphingomyelin synthase activity [148]. The activity on the cell surface may be relevant for the removal of Cer produced by signaling through the SM cycle. Importantly, this would result in the production of the signaling lipid diacylglycerol at the plasma membrane. Neither of the SM synthases has been cloned so far.

\subsection{Glycosphingolipids}

In the first step in the synthesis of complex glycosphingolipids in mammalian cells, Cer from the ER is glucosylated by the Cer glucosyltransferase (CGlcT) ([150]; Fig. 3). CGlcT has its active center on the cytosolic surface of the early Golgi $[110,142,151]$. However, part of the activity is ex- 
pressed in a hitherto undefined intracellular site, which has been proposed to be pre-Golgi or transGolgi [142,151]. No CGlcT was found in the ERGolgi intermediate compartment in Vero cells [152]. In the lumen of the Golgi [153], GlcCer is galactosylated to LacCer [154]. GlcCer thus occurs on both the cytosolic and non-cytosolic surface of cellular membranes. It is degraded in the lysosomes by the glucocerebrosidase [155], or at a different location by the non-lysosomal glucosylceramidase [123].

LacCer in the lumen of the Golgi can serve as a substrate for glycosyltransferases, each of which gives rise to a trihexosylceramide that is the precursor of a specific series of glycosphingolipids assembled by the stepwise addition of carbohydrate residues [156]. Most cells synthesize the ganglioside GM3, by the transfer of sialic acid to LacCer [157159], but in addition make one other trihexosylceramide. An interesting question is then how the flux into the two pathways is regulated [160].

Cell fractionation experiments have suggested that the sequential glycosyltransferases display concentration gradients along the cis-trans axis of the Golgi, with the highest concentration of the early acting transferases in the cis-Golgi (including the trihexosylceramide synthases) and the late acting transferases in the trans-Golgi and TGN [161-163]. Using similar methodology, a recent study assigned all lumenal transferases to the late Golgi, but with considerable overlap with the early Golgi [164]. Also here, the pharmacologic agent brefeldin $\mathrm{A}$ has been applied to discriminate the glycosyltransferases in the Golgi stack from those in the TGN. Glycosyltransferases that were still active in new glycosphingolipid synthesis after brefeldin treatment were supposedly transported back to the ER indicating their original localization in the Golgi stack, while those that no longer acted on newly synthesized glycosphingolipids were supposed to be located in the TGN [145,165167]. Similarly, monensin, which causes a block in membrane traffic between the cis-medial and transGolgi, possibly assigns the transferases that are still active in the synthesis of new glycosphingolipids [168-171], but no longer act on exogenously added glycosphingolipids [172], to the cis-medial Golgi [173]. These studies generally confirmed the presence of early acting and the absence of late acting transferases in the proximal Golgi. A tagged GalNAc transferase was not limited to the trans-Golgi [174] in contrast to predictions from brefeldin studies $[145,165]$. Whether or not this represents a transfection artefact has been critically discussed $[173,175]$. The physiological significance of the distribution of the transferases in the Golgi is as yet unclear.

Besides GlcCer, certain mammalian cells, especially myelin-forming cells but in man also epithelial cells, also synthesize galactosylceramide (GalCer) by means of the ceramide galactosyltransferase ([176, 177]; Fig. 3). This enzyme belongs to the family of the glucuronosyltransferases [178,179]. Biochemical and morphological evidence has confirmed its localization on the lumenal surface of the ER [180]. It displays a strong preference for Cers carrying a 2-hydroxy fatty acid [181,182]. GalCer can be sulfated by a sulfotransferase in the lumen of the Golgi $[183,184]$.

\subsection{Inositolsphingolipids}

The production of IPC in yeast involves the transfer of the headgroup from phosphatidylinositol to phytoceramide, a reaction yielding diacylglycerol as a side product [119]. The IPC synthase, or an essential subunit thereof, is encoded by the AUR1 gene [185]. The AUR1 gene product forms the target of several potent antifungal agents and its homologs have now been identified in a wide variety of fungi [186]. The protein has recently been located to the yeast Golgi (T. Levine, S. Munro, in press). Whether IPC synthesis occurs in the lumen or on the cytosolic surface of the Golgi remains to be established. Subsequent mannosylation of IPC to yield MIPC most likely occurs in the Golgi lumen $[187,188]$. In the Golgi, MIPC is further converted into $\mathrm{M}(\mathrm{IP})_{2} \mathrm{C}$ by an inositolphosphotransferase. This reaction resembles the one yielding IPC and requires the IPT1 gene whose product exhibits a striking structural similarity to that of the AUR1 gene [189].

\section{Intracompartmental sphingolipid transport}

\subsection{Lateral diffusion}

Sphingolipids diffuse laterally in the plane of the membrane [190]. However, this diffusion does not 
result in a random distribution of sphingolipids over the membrane surface. Numerous indications have been presented that the sphingolipid domains that have been demonstrated in model membranes containing sphingolipid/glycerophospholipid mixtures also occur in natural membranes [191,192]. Although there are still major uncertainties concerning the composition, organization, size, lifetime and transbilayer arrangement of the domains, it is clear that sphingolipids segregate with cholesterol into patches, that these patches are less fluid than the bulk of the membrane, and that the patches, by a mechanism that is essentially not understood, are capable of interacting with certain proteins on both sides of the membrane. In the non-cytosolic leaflet these are the GPI proteins [192,193], on the cytosolic side proteins that carry two or more saturated fatty acyl chains [194]. Also transmembrane proteins have been found to interact with these domains, due to multiple acylation: the hemagglutinin of influenza virus in infected or transfected cells [194,195], or due to its $O$-glycosylation: sucrase-isomaltase [196], or for unknown reasons: MAL [197,198], ephrin B1 [199].

It was originally believed that sphingolipids and GPI proteins are clustered in large surface domains called caveolae. These are characterized by a protein coat on their cytosolic surface, consisting of the cholesterol binding protein caveolin [109,200,201]. However, it was soon realized that clusters, as defined by detergent insolubility [192,193], are also present in cells that do not contain caveolae [202,203], and that GPI proteins and glycosphingolipids are not present in large patches unless clustering is induced [204-207]. The latest evidence supports the idea that GPI proteins, (glyco)sphingolipids and cholesterol are aggregated in small clusters [208-210], and that oligomerization of these clusters or 'rafts' has functional consequences in, for example, activating signaling cascades [211-214]. In this respect, the hydrolysis of SM by the neutral sphingomyelinase may not generate a signaling ceramide, instead hydrolysis of $30-50 \%$ of the plasma membrane SM may just upset the raft balance of the plasma membrane. In contrast to the small size of sphingolipid rafts in normal plasma membranes, the apical surface of epithelial cells, notably that of intestinal epithelial cells, is essentially covered by sphingolipids and cholesterol [2]. It must therefore be one big raft [215].

\subsection{Transbilayer translocation}

The sphingoid bases, sphinganine, sphingosine, and phytosphingosine, and Cers essentially lack a polar headgroup (Fig. 2). This predicts that they translocate across cellular membranes spontaneously within seconds, as had been reported for diacylglycerol [216]. The rate of translocation across a phosphatidylcholine bilayer has been measured for diacylglycerol and Cer carrying a hydrophobic $\mathrm{C}_{5}$-DMB moiety as the $s n$-2-acyl and $N$-acyl, respectively. While $\mathrm{C}_{5}$-DMB-diacylglycerol translocated with a half-time of some $70 \mathrm{~ms}$, this was $22 \mathrm{~min}$ for the Cer [217]. The possibility therefore exists that an asymmetric distribution of Cer in a biomembrane is maintained sufficiently long for it to act as a substrate for an enzyme on one side of the membrane without becoming available to an enzyme on the opposite surface. This possibility is supported by evidence suggesting that cholesterol, which possesses a hydroxy moiety as the polar headgroup just like Cer, directly or indirectly needs an ATP-driven transporter for translocation from the cytosolic to the noncytosolic leaflet of the plasma membrane [218-221]. In contrast, $\mathrm{C}_{6}$-NBD-Cer, $\mathrm{C}_{6}$-Cers and Cers with two truncated chains rapidly cross the plasma membrane and the Golgi membrane because after addition to the outside of cells they are readily converted to SM in the Golgi [222-227], even at low temperature. This is also the case for exogenously added sphingoid bases, which reach the intracellular sites of Cer synthesis [228]. The phosphate in sphingoid phosphates prevents spontaneous translocation across lipid bilayers on a time scale of hours. If rapid transbilayer translocation would occur, this must be either protein-mediated or the pertinent cellular membrane does not have the properties of a lipid bilayer (which has been proposed for the ER, see [65]).

Bai and Pagano [217] also studied the half-times for translocation of $\mathrm{C}_{5}$-DMB-SM and $\mathrm{C}_{5}$-DMBphosphatidylcholine in liposomes, which were calculated to be 3 and $7 \mathrm{~h}$, respectively. After synthesis in the lumenal leaflet of the Golgi, an SM analog with two truncated chains and $\mathrm{C}_{6}-\mathrm{NBD}-\mathrm{SM}$ were found to be restricted to the lumenal leaflet of the Golgi membrane [142,225,226,229], implying that SM could not translocate from the non-cytosolic to the cyto- 
solic leaflet. This has indeed been observed for spinlabeled and $\mathrm{C}_{6}-\mathrm{NBD}$ analogs of $\mathrm{SM}$ in numerous studies on erythrocytes (see [230]), while also the reported difference in SM species between the outer and inner leaflets of the erythrocyte membrane could support the virtual absence of SM flip [64]. No evidence for short-chain SM flip towards the cytosolic leaflet of the plasma membrane was found in fibroblasts nor in the apical or basolateral plasma membrane domain of epithelial cells [231,232]. Similarly, no SM flip across plasma membranes or endocytotic membranes has been noted for $\mathrm{C}_{6}$-NBD-SM in studies on endocytotic recycling [233-240].

However, this absence of SM flip in the plasma membrane may temporarily change when (specific) cells are activated. First of all, an activity has been noted in erythrocytes and blood platelets that scrambles the asymmetric distribution of the phospholipids in the plasma membrane, and an abundantly expressed 'scramblase' has been purified and its cDNA cloned [241,242]. Evidence has been presented that scramblase action flips SM to the cytosolic surface [243], whereas others have not observed this [244]. As a result of some stimuli SM must reach the cytosolic leaflet of the plasma membrane to serve as a substrate for the neutral sphingomyelinase (see Section 3.1). This could be mediated by the activation of the scramblase, but, alternatively, SM could flip across the membrane in a more proximal part of the secretory pathway. Indeed, evidence has been provided for a bidirectional translocation of phospholipids across the ER membrane, whereby SM translocation was slower than that of the glycerophospholipids [245,246]. Whether this rapid flip-flop is due to a 'flippase' or to non-bilayer structures in the ER membrane has been debated for years [65]. A flip of $\mathrm{C}_{6}$-NBD-SM from the lumenal to the cytoplasmic leaflet of the ER has also been inferred from studies using brefeldin A to fuse the Golgi with the ER. Under those conditions newly synthesized $\mathrm{C}_{6}$ NBD-SM was able to leave the mixed ER-Golgi compartment in the absence of vesicular traffic [74,147]. These studies demonstrated that plasma membranes contain proteins that can translocate (flop) $\mathrm{C}_{6}-\mathrm{NBD}-\mathrm{SM}$ from the cytosolic surface to the outer surface of the plasma membrane, and have identified the major multidrug transporters MDR1 P-glycoprotein and MRP1 as lipid translocators [74,147,247]. Whether these proteins can actually translocate natural SM, and whether this is of physiological relevance is an open question.

As for phospholipids, the spontaneous transbilayer translocation of glycosphingolipids across lipid bilayers is thought to be slow. However, GlcCer, the precursor of the complex glycosphingolipids, is synthesized on the cytosolic surface of the Golgi and conversion to LacCer occurs on the opposite side of the Golgi membrane, in the Golgi lumen. In experiments on isolated Golgi membranes, newly synthesized LacCer and more complex glycosphingolipids did not translocate to the cytosolic surface. The data suggest that an energy-independent GlcCer translocator is present in the Golgi membrane $[153,164,229]$. Studies on transport of short-chain analogs of GlcCer to the cell surface have demonstrated that the multidrug transporters that transport $\mathrm{C}_{6}$-NBD-SM, MDR1 P-glycoprotein and MRP1 translocate GlcCer analogs as well [74,147,247]. Although MDR1 was found to translocate a variety of short-chain lipids, its absence or presence has been selectively correlated with the concentration of natural GlcCer [248,249], which supports the notion that it is a real GlcCer translocase or floppase (R. Raggers, D. Sillence, G. van Meer, submitted). Its physiological function is as yet unclear. $\mathrm{C}_{6}-\mathrm{NBD}-\mathrm{GlcCer}$ can translocate from the outer leaflet to the cytosolic leaflet of the plasma membrane of fibroblasts [238]. However, studies in many other cell types have provided no evidence for such inward translocation [235,239,240,250-252].

The other monohexosyl glycosphingolipid, GalCer, is synthesized in the lumen of the ER (see Section 4.3). In isolated ER, newly synthesized GalCer carrying a $\mathrm{C}_{6}$-hydroxy fatty acid rapidly became accessible on the cytosolic surface. When added to Golgi membranes from MDCK cells, this GalCer analog was galactosylated to GalGalCer and sulfated to SGalCer, sulfatide. Both products were inaccessible to bovine serum albumin in the medium, implying that GalCer translocated to the Golgi lumen and that the products were unable to translocate back out [229]. A small fraction of the complex glycosphingolipids, like Forssman glycolipid, is present in the ER and the nuclear membrane with which it is continuous. The question whether these complex glycosphingo- 
lipids can translocate across the ER membrane to its cytosolic surface has not been addressed.

\section{Intercompartmental sphingolipid transport}

\subsection{Vesicular pathways}

Cer is synthesized in the ER. In some cells, part of the Cer is converted to GalCer in the ER. However, Cer must be transported to the Golgi for synthesis of GlcCer and SM, or IPC (Fig. 3). Some evidence has been presented that Cer would not be present in the transport vesicles that leave the ER for the Golgi [283], and that Cer is still transported in the absence of vesicular traffic. For that reason Cer transport will be addressed in Section 6.2. GalCer, though synthesized in the ER, occurs in high concentration on the cell surface of myelin-producing cells and of many epithelial cells [2]. Again, there is no reason why GalCer would not follow the vesicular traffic from the ER to the Golgi, but it is unclear whether there is any GalCer aggregation at the site of ER vesicle budding, or that such reactions only start in the Golgi, as they may require a certain threshold concentration of sphingolipids. A similar question concerns the complex glycosphingolipids in the ER: a small but significant fraction of Forssman glycolipid was found in the ER/nuclear membrane [107]. It seems necessary that these complex lipids, and SM, must be continuously removed from the ER, but it is as yet unclear how this works.

On the cytosolic surface of the Golgi, part of Cer is glucosylated to GlcCer. From here, GlcCer may follow three pathways, none of which can be excluded at present: (1) It can translocate across the Golgi membrane, evidence for which has been found in vitro (Section 5.2), and can be (partially?) converted to higher glycosphingolipids. GlcCer and the higher glycosphingolipids may then leave the Golgi on the lumenal side of transport vesicles; (2) GlcCer may leave the Golgi on the cytosolic surface of secretory vesicles, and subsequently undergo translocation to the outer leaflet of the plasma membrane (by MDR1 P-glycoprotein? Section 5.2). Alternatively, along the retrograde pathway, GlcCer might be translocated across the ER membrane, after which it would have a fate similar to newly synthesized
GalCer; (3) GlcCer might leave the cytosolic surface of Golgi membrane by desorption from the membrane and monomeric exchange with another organelle's cytosolic surface (Section 6.2). Good evidence has been presented that higher glycosphingolipids follow a vesicular transport pathway from their site of assembly in the lumen of the Golgi to the plasma membrane. This was demonstrated for the early ganglioside GM3 [92], and for the late ganglioside GD1a [91].

In the lumen of the Golgi, Cer is converted to SM. SM does not translocate to the cytosolic surface (Section 5.2). Besides the logic that lumenal sphingolipids can only be shuttled between organelles via the lumenal side of transport vesicles, all evidence supports traffic on the lumenal surface of carrier vesicles as the major path of SM transport in the cell. After synthesis in the Golgi lumen, SM is transported to the plasma membrane. Transport was severely reduced in mitotic cells where vesicular transport is known to be inhibited [74]. In various cell lines, transport of radiolabeled SM to the plasma membrane, as measured by accessibility to exogenous sphingomyelinase or by cell fractionation, was inhibited by pretreating the cells with brefeldin A [74,253255], which fuses the Golgi stack to the ER and blocks vesicular traffic of proteins from the Golgi to the plasma membrane. In the case where brefeldin did not inhibit transport, in hepatocytes [73], as stated above, the SM synthase appears to be situated beyond the brefeldin block [144]. After synthesis of an SM with two shortened chains, it was found inside transport vesicles $[225,226]$. Transport depended on cytosolic proteins and ATP, was inhibited by GTP $\gamma$, and transport of this SM and of $\mathrm{C}_{6}-\mathrm{NBD}-$ $\mathrm{SM}$ was strongly temperature-dependent with complete inhibition below $10-15^{\circ} \mathrm{C}$, the temperature where vesicular traffic of proteins is blocked $[225,252,256]$. Transport of $\mathrm{C}_{6}$-NBD-SM was inhibited in mitotic cells [257]. Brefeldin could not be used as an assay for vesicular traffic, as, in this case, the short-chain SM escapes from the fused ER-Golgi by monomeric transport [74,147]. Experiments performed with late secretory mutants in yeast revealed that, like SM and the complex glycosphingolipids in mammalian cells, the inositol sphingolipids depend on vesicular traffic for reaching the plasma membrane [258]. 
As the sphingolipids are synthesized in organelles along the secretory pathway, and as they diffuse laterally in the membrane, they should flow along this pathway in both directions and randomly distribute over the connected organelles unless they are restricted. The fact that sphingolipids after synthesis in the Golgi are enriched in the plasma membrane, and are hardly present in the ER, suggests just such a restriction. The sphingolipids would thus be preferentially included into vesicles directed in the anterograde direction or would be prevented from entering the opposite, retrograde pathway (Fig. 1). Both possibilities are the consequence of the same phenomenon, the clustering of sphingolipids (and cholesterol) that was discussed earlier. Of course, clustering by itself would not result in directionality in a vesicular pathway. Since the targeting of transport vesicles depends on the presence of specific targeting molecules, notably a specific SNARE (see $[259,260]$ ), the sphingolipid domains are predicted to incorporate a particular molecule of this family.

Originally, the argument was proposed that, to maintain the enrichment of glycosphingolipids on the apical plasma membrane domain of epithelial cells, glycosphingolipid domains must exit in the lumenal leaflet of the TGN and that they must be specifically included into transport vesicles with an apical destination [2,224]. Whereas in the cis-Golgi sphingolipids would have to be segregated from glycerolipids, in the TGN glycosphingolipids would be segregated from SM and glycerophospholipids which are basolaterally enriched in these cells [261]. The actual lipid composition of the domains must therefore change with the overall change in lipid composition along the secretory pathway. Although the mechanism of sphingolipid domain-mediated sorting has by no means been solved, the first proteins that preferentially interact with sphingolipid/cholesterol domains and may be part of the sorting machinery have now been identified [3]. Amongst these are the first parts of the SNARE machinery that provide targeting specificity to the apical transport vesicles [262]. Furthermore, it has become clear that a number of membrane proteins for their proper targeting depend on sphingolipids and cholesterol. Amongst these are GPI proteins, in kidney epithelial cells [263] and in yeast [264], which also displays typical sphingolipid domains [265], and membrane-spanning proteins like the hemagglutinin of influenza virus $[195,266,267]$ and sucrase-isomaltase [196].

Vesicular traffic does not stop at the plasma membrane. Endocytotic traffic of $\mathrm{C}_{6}-\mathrm{NBD}-\mathrm{SM}$ has been followed in various cell types. In these studies, $\mathrm{C}_{6}$ NBD-SM displayed the kinetics of bulk membrane transport as defined by the transferrin receptor [236,237], and while most SM recycled, a small fraction ended up in the lysosomes for degradation [233235]. From the cell surface, also $\mathrm{C}_{6}-\mathrm{NBD}-\mathrm{GlcCer}$ and $\mathrm{C}_{6}$-NBD-GalCer followed vesicular recycling in a number of studies [235,239,240,250-252]. Sorting during endocytotic recycling was observed between $\mathrm{C}_{6}$-NBD-GlcCer and $\mathrm{C}_{6}$-NBD-SM [235,239,240]. This was then interpreted as reflecting lateral segregation in the lumenal membrane leaflet of an intracellular recycling compartment. However, it would be somewhat unexpected if $\mathrm{C}_{6}$-NBD-lipid sorting via domains would accurately reflect sorting of their natural counterparts because the necessary aggregation of the sphingolipids largely depends on the lipid backbone [192,192], which is dramatically distorted in $\mathrm{C}_{6}$-NBD-lipids [268]. The original finding of $\mathrm{C}_{6}$ NBD-lipid sorting in epithelial cells [224] later turned out not to be due to lateral lipid segregation in the TGN, but to preferential transport of $\mathrm{C}_{6}$ NBD-GlcCer across the apical plasma membrane domain by a multidrug transporter whereas $\mathrm{C}_{6}$ NBD-SM was transported to both surfaces by vesicular transport [74,147]. No sorting between $\mathrm{C}_{6}$ NBD-GlcCer and $\mathrm{C}_{6}$-NBD-GalCer was observed in the transcytotic pathway in kidney epithelial cells [252]. Actually, in this study $\mathrm{C}_{6}$-NBD-GlcCer was shown to be an excellent marker for bulk membrane transport along the transcytotic pathway. It has been used as such in studying endocytosis [269]. In one study, $\mathrm{C}_{6}$-NBD-GlcCer escaped vesicular endocytosis by an unknown mechanism [238].

The glycosphingolipids GM1 and $\mathrm{Gb}_{3}$ can act as receptors for the bacterial toxins cholera toxin (see [90]) and Shiga toxin [270], respectively. These toxins need to reach the ER, where they translocate across the membrane to become active in the cytosol. Endocytotic transport of the toxin-glycosphingolipid complex has provided information on vesicular transport pathways from sphingolipid domains on the plasma membrane to the ER [271-275]. Retrograde transport of the complexes may be driven by 
protein sequences in the toxin [276-279], and the transport efficiency of free glycosphingolipids to the ER is unclear. Finally, vesicular traffic of sphingolipids can be expected to display the full complement of properties that characterize vesicular transport of proteins, like dependence on energy and cytosolic proteins (coats, SNAREs, cytoskeleton), which are not reviewed in detail here.

\subsection{Monomeric exchange}

Sphinganine, sphingosine, and phytosphingosine are single-chain lipids that probably exchange readily between membranes through the aqueous phase in monomeric form. Even sphingoid bases carrying a shortened acyl chain rapidly transfer between membranes [146,217,222]. Short-chain Cers have been used to characterize sphingolipid synthesis and transport in numerous studies since Lipsky and Pagano [222]. Because exogenous sphingoid bases rapidly translocate across membranes, they can efficiently reach the site of Cer synthesis [280]. In order to prevent cellular loss of sphingoid bases it seems required that they are efficiently trapped in the ER by metabolism. This is the more relevant as it was observed that most of the sphingoid bases used for the synthesis of ceramide may actually be derived from sphingolipid hydrolysis in the lysosomes [281]. Phosphorylated sphingoid bases, like sphingosine-1phosphate, will exchange as monomers very rapidly. However, in combination with a low rate of transbilayer translocation this may still allow a physical separation between two signaling pools: (1) exogenous sphingosine-1-phosphate, signaling at the outside of the plasma membrane, and (2) a sphingosine1-phosphate pool freely exchanging between the cytosolic surfaces of all organelles and exerting intracellular second messenger functions. The second pool is expected to overlap with the pool destined for degradation as the responsible lyase has been assigned to the cytosolic surface of the ER [132].

While Cer is produced on the cytosolic surface of the ER, its conversion into GlcCer takes place on the cytosolic surface of the Golgi apparatus and its conversion into $\mathrm{SM}$ in the Golgi lumen. The mechanism(s) by which Cer is moved from the ER to the sites of GlcCer and SM production in the Golgi is unclear. ER-derived transport vesicles enriched in
Cer fused with Golgi membranes in an $N$-ethylmaleimide-sensitive manner under cell-free conditions [282]. In another cell-free system, the opposite conclusion was reached, namely that Cer is largely excluded from ER-derived transport vesicles and can reach the Golgi via a non-vesicular pathway which is ATP-independent and $N$-ethylmaleimide-insensitive [283]. Consistent with the existence of a nonvesicular pathway for Cer transport, the conversion of Cer into SM and GlcCer continued in mitotic HeLa cells, in which transport of newly synthesized membrane proteins is blocked [284]. However, with respect to the latter study, it should be noted that the issue of whether the disassembly of the Golgi complex during mitosis involves its fusion with the ER or not remains to be settled [285].

In intact and streptolysin O-permeabilized cells, the de novo synthesis of GlcCer from metabolically labeled Cer was sustained under various conditions that abolished ER-to-Golgi trafficking of VSV-G protein [286]. On the basis of these results, the authors concluded that Cer transfer from ER to Golgi does not depend on vesicular carriers that mediate protein transport. However, in the same assays the de novo synthesis of SM from metabolically labeled Cer was found to be both energy- and temperaturedependent. In agreement with this, genetic evidence was recently provided for the existence of an ATPdependent trafficking pathway of Cer from the ER to the site of SM synthesis in the Golgi [287]. Here, the authors took advantage of an SM-directed cytolysin to isolate $\mathrm{CHO}$ cell mutants with specific defects in SM synthesis. One of the mutant strains, LY-A, displayed a specific defect in the conversion of Cer into SM which was unrelated to alterations in enzymatic activities responsible for SM synthesis or breakdown. Pulse-chase experiments with a fluorescent $\mathrm{Cer}\left(\mathrm{C}_{5}\right.$ DMB-Cer) revealed that in wild-type cells $\mathrm{C}_{5}$-DMBCer was redistributed from intracellular membranes to the Golgi in an ATP-dependent fashion, and that LY-A cells were defective in this energy-dependent redistribution. On the other hand, glycosphingolipid production and ER-to-Golgi trafficking of GPIanchored or transmembrane proteins in LY-A cells appeared to be normal. The authors proposed that the delivery of Cer from the ER to the sites of sphingolipid synthesis in the Golgi is mediated by two pathways: an ATP-independent, non-vesicular path- 
way for glycosphingolipid synthesis and an ATP-dependent pathway for SM production. Several possibilities can be put forward to explain the preferential ATP-dependent delivery of Cer to the site of SM synthesis: (1) Cer might reach the Golgi primarily by a non-vesicular pathway involving Cer-specific transfer proteins and/or close contacts between ER and Golgi membranes (see [288]). In that case, Cer might require ATP-stimulated translocation across the Golgi membrane in order to reach the site of SM synthesis. Flip-flop of natural Cer may be slow [217], and from the new data on a potential ATPdependent cholesterol translocator (Section 5.2), it seems possible that Cer has to be pumped against a concentration gradient, and that a higher concentration in the cytosolic leaflet would be maintained by preferential interactions, maybe even by some sort of domain organization on the cytosolic surface; (2) SM synthesis might occur in a sub-Golgi compartment distal to that involved in GlcCer synthesis (see Section 4.2). In this scenario, SM synthesis requires not only ER-to-Golgi, but also intra-Golgi transport of Cer, the latter being ATP-dependent; (3) There might be multiple, independent vesicular transport pathways from the ER to the Golgi, one of which is exclusive for Cer.

The existence of a non-classical vesicular transport mechanism for Cer can also be surmised from studies with early secretory mutants in yeast. In this organism, the production of IPC was found to be largely independent of genes whose products control protein trafficking from the ER to the Golgi [289]. As IPC synthase has recently been located to the Golgi (Section 4.4), a tentative interpretation of the data is that newly synthesized Cer in yeast can reach the Golgi independently of the machinery responsible for vesicular ER-to-Golgi transport of proteins. However, it is important to realize that many Golgi-resident proteins, including Golgi enzymes, have been shown to recycle to the ER [290,291] and may accumulate there in significant amounts when membrane transport out of the ER is blocked (for example, see [19]). If the same holds true for enzymes responsible for sphingolipid assembly in the Golgi, then some of the experimental data discussed above may require a reinterpretation. Clearly, additional studies are needed to establish the precise nature of the pathway(s) used for intercompartmental Cer transport. Identification of the gene affected in the LY-A mutant strain could provide an important step forward in defining the molecular mechanism(s) underlying the intracellular trafficking of Cer.

After conversion of Cer to its various sphingolipid products, only GlcCer is present on the cytosolic surface of the Golgi (Section 3.3). Possibly, also GalCer has access to the cytosolic surface of the ER and thereby other membranes along the secretory pathway (Section 5.2). This orientation allows desorption into the cytosol and monomeric transport to other organelles. Indeed, evidence has been presented that GlcCer (and not SM) still reached the plasma membrane when vesicular traffic was inhibited by brefeldin A [255]. Because the spontaneous exchange of GlcCer, SM, and other glycosphingolipids through the water phase is very slow (half-time of days [292]), transfer would be expected to occur at sites of close membrane contact [293] or it should be stimulated by the presence of glycosphingolipid transfer proteins. Such a protein has been isolated from cytosol [294,295], and its cDNA has been cloned [296]. It is capable of transferring a variety of glycosphingolipids between membranes in vitro. Its function in vivo is unclear. Other proteins that stimulate monomeric glycosphingolipid transfer in vitro have been found to be involved in lysosomal glycosphingolipid hydrolysis (see [297]), and not intercompartmental transport.

Under some conditions, SM has been found in mitochondria (Section 3.1). Since no vesicular transport occurs to the mitochondria, the mechanism of transport of SM to the mitochondria was most likely monomeric. It will be interesting why SM is available for monomeric transfer under those conditions and whether there is a function for an SM transfer protein $[298,299]$.

\section{Perspectives}

Evidence from the past few years has strengthened the notion that sphingolipids are particularly relevant for the cellular physiology by their property to cluster with cholesterol in the plane of the membrane. These clusters, called microdomains or rafts, seem most important for organizing signaling events at the plasma membrane and for sorting and targeting 
membrane proteins and lipids to their proper destinations along the cell's vesicular highways. In that way, sphingolipids can be viewed as vital parts of the machinery by which a cell ensures the proper functioning of its secretory and endocytic organelles, including the plasma membrane. It has now become clear from the many different types of sphingolipids, each with its own specific physical properties, and from the multitude of proteins involved in their metabolism and transport, that there is more to sphingolipids than just their property to segregate from glycerophospholipids in liposomes. When thinking about raft function in the various organelles, each with its own typical lipid and protein composition, it is clear that we completely lack insight into the fine tuning of the raft system.

Presently, exciting progress is being made with the identification and localization of protein factors involved in the regulation of raft assembly and trafficking. These are first of all the biosynthetic and hydrolytic enzymes of sphingolipid metabolism, some of which have been found at quite unexpected locations. Moreover, the first translocators have been identified that flip sphingolipids from one leaflet of the bilayer, across into the opposite leaflet, although at present it is fully unclear how such translocations are connected to the raft principle. Also the first targeting factors have been identified for one specific raftmediated transport step, namely that between the TGN and the apical membrane of epithelial cells. Still, the genes encoding major synthetic enzymes (e.g. the ceramide and sphingomyelin synthases), hydrolytic enzymes (e.g. the non-lysosomal glucosylceramidase), and translocators, (e.g. the Golgi glucosylceramide importer) have escaped molecular cloning. Other proteins, for example those that are able to specifically bind sphingomyelin or monohexosylceramides, have been identified and sequenced, but their physiological functions remain enigmatic.

In the next phase of unraveling sphingolipid physiology, one of the main challenges will be to define the parameters of the raft framework that must be regulated (size, i.e. degree of aggregation, and molecular composition, which will have to be different for each organelle and each membrane leaflet), to identify the effectors of the regulation (components regulating sphingolipid metabolism and flow), and the factors that govern their activity. A subsequent ques- tion will then be, what are the sensors that govern the regulatory activities? Probably, we will have to wait until the regulatory loops have been characterized before we obtain insight into the really important functions of sphingolipids. Only recently have we learned that even eliminating a subclass of sphingolipids in mammals, namely the glucosphingolipids, is embryonically lethal [300]. In order to understand this, it seems wise to start with unraveling sphingolipid physiology at the level of a single cell. For this purpose, yeast provides an attractive model system, as it will most likely be the first organism in which the full set of genes involved in sphingolipid metabolism is known. When combined with DNA microarray technology, this information would create a unique starting point to determine how sphingolipid metabolism is integrated with other cellular processes that are fundamental for eukaryotic life, like cell growth, membrane trafficking and the capacity to cope with environmental stress. Lessons learned from yeast will provide a useful base from which to work our way up to the multicellular organisms that are genetically amenable like Drosophila and Caenorhabditis elegans, an approach that has already started to disclose new elements of raft physiology $[301,302]$. However, let us be modest. The mere fact that sphingolipid variety coevolved with the organisms over many millions of years should tell us that we still have a long way to go before we will be able to appreciate the full detail of their beneficial effects for human life.

\section{Acknowledgements}

We dedicate this work to Mara, daughter of our friend and colleague Thomas Pomorski and Ines Günther, born August 14, 1999. We are grateful to all our friends and colleagues for sharing their newest data and for critical assessment of our statements, and to the editors for encouragement.

\section{References}

[1] M.A. Chester, IUPAC-IUB Joint Commission on Biochemical Nomenclature (JCBN). Nomenclature of glycolipids. Recommendations 1997, Eur. J. Biochem. 257 (1998) 293298. 
[2] K. Simons, G. van Meer, Lipid sorting in epithelial cells, Biochemistry 27 (1988) 6197-6202.

[3] K. Simons, E. Ikonen, Functional rafts in cell membranes, Nature 387 (1997) 569-572.

[4] D.A. Brown, E. London, Functions of lipid rafts in biological membranes, Annu. Rev. Cell Dev. Biol. 14 (1998) 111136.

[5] A. Rietveld, K. Simons, The differential miscibility of lipids as the basis for the formation of functional membrane rafts, Biochim. Biophys. Acta 1376 (1998) 467-479.

[6] K. Hanada, M. Nishijima, M. Kiso, A. Hasegawa, S. Fujita, T. Ogawa, Y. Akamatsu, Sphingolipids are essential for the growth of Chinese hamster ovary cells. Restoration of the growth of a mutant defective in sphingoid base biosynthesis by exogenous sphingolipids, J. Biol. Chem. 267 (1992) 23527-23533.

[7] J.L. Patton, B. Srinivasan, R.C. Dickson, R.L. Lester, Phenotypes of sphingolipid-dependent strains of Saccharomyces cerevisiae, J. Bacteriol. 174 (1992) 7180-7184.

[8] R.C. Dickson, Sphingolipid functions in Saccharomyces cerevisiae: Comparison to mammals, Annu. Rev. Biochem. 67 (1998) 27-48.

[9] Y.A. Hannun, The sphingomyelin cycle and the second messenger function of ceramide, J. Biol. Chem. 269 (1994) 31253128.

[10] R. Kolesnick, Z. Fuks, Ceramide: A signal for apoptosis or mitogenesis?, J. Exp. Med. 181 (1995) 1949-1952.

[11] S. Spiegel, Sphingosine 1-phosphate: a prototype of a new class of second messengers, J. Leukocyte Biol. 65 (1999) 341344.

[12] H.R. Pelham, Sorting and retrieval between the endoplasmic reticulum and Golgi apparatus, Curr. Opin. Cell Biol. 7 (1995) 530-535.

[13] M. Aridor, J. Weissman, S. Bannykh, C. Nuoffer, W.E. Balch, Cargo selection by the COPII budding machinery during export from the ER, J. Cell Biol. 141 (1998) 61-70.

[14] W. Nickel, B. Brugger, F.T. Wieland, Protein and lipid sorting between the endoplasmic reticulum and the Golgi complex, Semin. Cell Dev. Biol. 9 (1998) 493-501.

[15] J.M. Herrmann, P. Malkus, R. Schekman, Out of the ER outfitters, escorts and guides, Trends Cell Biol. 9 (1999) 5-7.

[16] J.E. Rothman, F.T. Wieland, Protein sorting by transport vesicles, Science 272 (1996) 227-234.

[17] J. Fullekrug, T. Nilsson, Protein sorting in the Golgi complex, Biochim. Biophys. Acta 1404 (1998) 77-84.

[18] A. Mironov, A. Luini, A synthetic model of intra-Golgi traffic, FASEB J. 12 (1998) 249-252.

[19] S. Wooding, H.R. Pelham, The dynamics of Golgi protein traffic visualized in living yeast cells, Mol. Biol. Cell 9 (1998) 2667-2680.

[20] B.B. Allan, W.E. Balch, Protein sorting by directed maturation of Golgi compartments, Science 285 (1999) 63-66.

[21] G. Griffiths, K. Simons, The trans Golgi network: sorting at the exit site of the Golgi complex, Science 234 (1986) 438443.

[22] E. Conibear, T.H. Stevens, Multiple sorting pathways be- tween the late Golgi and the vacuole in yeast, Biochim. Biophys. Acta 1404 (1998) 211-230.

[23] R. Le Borgne, B. Hoflack, Protein transport from the secretory to the endocytic pathway in mammalian cells, Biochim. Biophys. Acta 1404 (1998) 195-209.

[24] C. Thiele, W.B. Huttner, Protein and lipid sorting from the trans-Golgi network to secretory granules. Recent developments, Semin. Cell Dev. Biol. 9 (1998) 511-516.

[25] F. Gu, J. Gruenberg, Biogenesis of transport intermediates in the endocytic pathway, FEBS Lett. 452 (1999) 61-66.

[26] S. Mukherjee, R.N. Ghosh, F.R. Maxfield, Endocytosis, Physiol. Rev. 77 (1997) 759-803.

[27] B. Wendland, S.D. Emr, H. Riezman, Protein traffic in the yeast endocytic and vacuolar protein sorting pathways, Curr. Opin. Cell Biol. 10 (1998) 513-522.

[28] P.J. Meier, M.A. Spycher, U.A. Meyer, Isolation of a subfraction of rough endoplasmic reticulum closely associated with mitochondria. Evidence for its role in cytochrome P450 synthesis, Exp. Cell Res. 111 (1978) 479-483.

[29] J.E. Vance, Phospholipid synthesis in a membrane fraction associated with mitochondria, J. Biol. Chem. 265 (1990) 7248-7256.

[30] B. Gaigg, R. Simbeni, C. Hrastnik, F. Paltauf, G. Daum, Characterization of a microsomal subfraction associated with mitochondria of the yeast, Saccharomyces cerevisiae. Involvement in synthesis and import of phospholipids into mitochondria, Biochim. Biophys. Acta 1234 (1995) 214-220.

[31] G. Daum, J.E. Vance, Import of lipids into mitochondria, Prog. Lipid Res. 36 (1997) 103-130.

[32] T.W. Keenan, D.J. Morré, Phospholipid class and fatty acid composition of Golgi apparatus isolated from rat liver and comparison with other cell fractions, Biochemistry 9 (1970) 19-25.

[33] A. Colbeau, J. Nachbaur, P.M. Vignais, Enzymic characterization and lipid composition of rat liver subcellular membranes, Biochim. Biophys. Acta 249 (1971) 462-492.

[34] F. Zambrano, S. Fleischer, B. Fleischer, Lipid composition of the Golgi apparatus of rat kidney and liver in comparison with other subcellular organelles, Biochim. Biophys. Acta 380 (1975) 357-369.

[35] P. Moreau, C. Cassagne, Phospholipid trafficking and membrane biogenesis, Biochim. Biophys. Acta 1197 (1994) 257290.

[36] R. Henning, H.D. Kaulen, W. Stoffel, Biochemical analysis of the pinocytotic process. I. Isolation and chemical composition of the lysosomal and the plasma membrane of the rat liver cell, Hoppe Seyler's Z. Physiol. Chem. 351 (1970) 11911199.

[37] W.H. Evans, W.G.M. Hardison, Phospholipid, cholesterol, polypeptide and glycoprotein composition of hepatic endosome subfractions, Biochem. J. 232 (1985) 33-36.

[38] J.D. Belcher, R.L. Hamilton, S.E. Brady, C.A. Hornick, S. Jaeckle, W.J. Schneider, R.J. Havel, Isolation and characterization of three endosomal fractions from the liver of estradiol-treated rats, Proc. Natl. Acad. Sci. USA 84 (1987) 67856789. 
[39] L.D. Bergelson, E.V. Dyatlovitskaya, T.I. Torkhovskaya, I.B. Sorokina, N.P. Gorkova, Phospholipid composition of membranes in the tumor cell, Biochim. Biophys. Acta 210 (1970) 287-298.

[40] L.D. Bergelson, E.V. Dyatlovitskaya, I.B. Sorokina, N.P. Gorkova, Phospholipid composition of mitochondria and microsomes from regenerating rat liver and hepatomas of different growth rate, Biochim. Biophys. Acta 360 (1974) 361-365.

[41] R.C. Reitz, J.A. Thompson, H.P. Morris, Mitochondrial and microsomal phospholipids of Morris hepatoma 7777, Cancer Res. 37 (1977) 561-567.

[42] K.Y. Hostetler, B.D. Zenner, H.P. Morris, Phospholipid content of mitochondrial and microsomal membranes from Morris hepatomas of varying growth rates, Cancer Res. 39 (1979) 2978-2983.

[43] D.W. Schwertz, J.I. Kreisberg, M.A. Venkatachalam, Characterization of rat kidney proximal tubule brush border membrane-associated phosphatidylinositol phosphodiesterase, Arch. Biochem. Biophys. 224 (1983) 555-567.

[44] M.K. Hise, W.W. Mantulin, E.J. Weinman, Fluidity and composition of brush border and basolateral membranes from rat kidney, Am. J. Physiol. 247 (1984) F434-F439.

[45] G. Carmel, F. Rodrigue, S. Carrière, C. Le Grimellec, Composition and physical properties of lipids from plasma membranes of dog kidney, Biochim. Biophys. Acta 818 (1985) 149-157.

[46] B.A. Molitoris, F.R. Simon, Renal cortical brush-border and basolateral membranes: cholesterol and phospholipid composition and relative turnover, J. Membr. Biol. 83 (1985) 207-215.

[47] G. van Meer, How epithelial cells grease their microvilli, Trends Biochem. Sci. 13 (1988) 242-243.

[48] S. Spiegel, G.R. Matyas, L. Cheng, B. Sacktor, Asymmetric distribution of gangliosides in rat renal brush-border and basolateral membranes, Biochim. Biophys. Acta 938 (1988) 270-278.

[49] G.G. Forstner, K. Tanaka, K.J. Isselbacher, Lipid composition of the isolated rat intestinal microvillus membrane, Biochem. J. 109 (1968) 51-59.

[50] K. Kawai, M. Fujita, M. Nakao, Lipid components of two different regions of an intestinal epithelial cell membrane of mouse, Biochim. Biophys. Acta 369 (1974) 222-233.

[51] A.J. Verkleij, R.F.A. Zwaal, B. Roelofsen, P. Comfurius, D. Kastelijn, L.L.M. van Deenen, The asymmetric distribution of phospholipids in the human red cell membrane. A combined study using phospholipases and freeze-etch electron microscopy, Biochim. Biophys. Acta 323 (1973) 178193.

[52] C. Venien, C. Le Grimellec, Phospholipid asymmetry in renal brush-border membranes, Biochim. Biophys. Acta 942 (1988) 159-168.

[53] D. Allan, P. Quinn, Membrane phospholipid asymmetry in Semliki Forest virus grown in BHK cells, Biochim. Biophys. Acta 987 (1989) 199-204.

[54] J.L. Whatmore, D. Allan, Phospholipid asymmetry in plas- ma membrane vesicles derived from BHK cells, Biochim. Biophys. Acta 1192 (1994) 88-94.

[55] M. Record, A. El Tamer, H. Chap, L. Douste-Blazy, Evidence for a highly asymmetric arrangement of ether- and diacyl-phospholipid subclasses in the plasma membrane of Krebs II ascites cells, Biochim. Biophys. Acta 778 (1984) 449-456.

[56] A. Rawyler, P.H. van der Schaft, B. Roelofsen, J.A.F. Op den Kamp, Phospholipid localization in the plasma membrane of Friend erythroleukemic cells and mouse erythrocytes, Biochemistry 24 (1985) 1777-1783.

[57] J.A. Post, G.A. Langer, J.A.F. Op den Kamp, A.J. Verkleij, Phospholipid asymmetry in cardiac sarcolemma. Analysis of intact cells and 'gas-dissected' membranes, Biochim. Biophys. Acta 943 (1988) 256-266.

[58] R.M. Buckland, G.K. Radda, C.D. Shennan, Accessibility of phospholipids in the chromaffin granule membrane, Biochim. Biophys. Acta 513 (1978) 321-337.

[59] Y. Zhang, R. Kolesnick, Signaling through the sphingomyelin pathway, Endocrinology 136 (1995) 4157-4160.

[60] S. Tomink, M. Zumbansen, W. Stoffel, Characterization and subcellular localization of murine and human magnesiumdependent neutral sphingomyelinase, J. Biol. Chem. 275 (2000) 5710-5717.

[61] C.M. Linardic, Y.A. Hannun, Identification of a distinct pool of sphingomyelin involved in the sphingomyelin cycle, J. Biol. Chem. 269 (1994) 23530-23537.

[62] N. Andrieu, R. Salvayre, T. Levade, Comparative study of the metabolic pools of sphingomyelin and phosphatidylcholine sensitive to tumor necrosis factor, Eur. J. Biochem. 236 (1996) 738-745.

[63] C. Bezombes, N. Maestre, G. Laurent, T. Levade, A. Bettaieb, J.P. Jaffrézou, Restoration of TNF-alpha-induced ceramide generation and apoptosis in resistant human leukemia KG1a cells by the p-glycoprotein blocker PSC833, FASEB J. 12 (1998) 101-109.

[64] J.P.J. Boegheim Jr., M. van Linde, J.A.F. Op den Kamp, B. Roelofsen, The sphingomyelin pools in the outer and inner layer of the human erythrocyte membrane are composed of different molecular species, Biochim. Biophys. Acta 735 (1983) 438-442.

[65] G. van Meer, The lipid bilayer of the ER. Trends Biochem. Sci. 11 (1986) 194-195, 401.

[66] G. Lipka, J.A.F. Op den Kamp, H. Hauser, Lipid asymmetry in rabbit small intestinal brush border membrane as probed by an intrinsic phospholipid exchange protein, Biochemistry 30 (1991) 11828-11836.

[67] G. van Meer, K. Simons, J.A.F. Op den Kamp, L.L.M. van Deenen, Phospholipid asymmetry in Semliki Forest virus grown on baby hamster kidney (BHK-21) cells, Biochemistry 20 (1981) 1974-1981.

[68] D.J. Sillence, R.J. Raggers, G. van Meer, Assays for the transmembrane movement of sphingolipids. Methods Enzymol. (2000) in press.

[69] R. Sundler, A.W. Alberts, P.R. Vagelos, Phospholipases as probes for membrane sideness. Selective analysis of the outer 
monolayer of asymmetric bilayer vesicles, J. Biol. Chem. 253 (1978) 5299-5304.

[70] Y. Lange, M.H. Swaisgood, B.V. Ramos, T.L. Steck, Plasma membranes contain half the phospholipid and $90 \%$ of the cholesterol and sphingomyelin in cultured human fibroblasts, J. Biol. Chem. 264 (1989) 3786-3793.

[71] G. Griffiths, R. Back, M. Marsh, A quantitative analysis of the endocytic pathway in baby hamster kidney cells, J. Cell Biol. 109 (1989) 2703-2720.

[72] D. Allan, P. Quinn, Resynthesis of sphingomyelin from plasma-membrane phosphatidylcholine in BHK cells treated with Staphylococcus aureus sphingomyelinase, Biochem. J. 254 (1988) 765-771.

[73] Y.-J. Shiao, J.E. Vance, Sphingomyelin transport to the cell surface occurs independently of protein secretion in rat hepatocytes, J. Biol. Chem. 268 (1993) 26085-26092.

[74] A. van Helvoort, M.L. Giudici, M. Thielemans, G. van Meer, Transport of sphingomyelin to the cell surface is inhibited by brefeldin $\mathrm{A}$ and in mitosis, where $\mathrm{C}_{6}$-NBD-sphingomyelin is translocated across the plasma membrane by a multidrug transporter activity, J. Cell Sci. 110 (1997) 75-83.

[75] V. Gieselmann, Lysosomal storage diseases, Biochim. Biophys. Acta 1270 (1995) 103-136.

[76] B. Otterbach, W. Stoffel, Acid sphingomyelinase-deficient mice mimic the neurovisceral form of human lysosomal storage disease (Niemann-Pick disease), Cell 81 (1995) 10531061.

[77] E.D. Carstea, J.A. Morris, K.G. Coleman, S.K. Loftus, D. Zhang, C. Cummings, J. Gu, M.A. Rosenfeld, W.J. Pavan, D.B. Krizman, J. Nagle, M.H. Polymeropoulos, S.L. Sturley, Y.A. Ioannou, M.E. Higgins, M. Comly, A. Cooney, A. Brown, C.R. Kaneski, E.J. Blanchette-Mackie, N.K. Dwyer, E.B. Neufeld, T.-Y. Chang, L. Liscum, J.F. Strauss III, K. Ohno, M. Zeigler, R. Carmi, J. Sokol, D. Markie, R.R. O’Neill, O.P. van Diggelen, M. Elleder, M.E. Patterson, R.O. Brady, M.T. Vanier, P.G. Pentchev, D.A. Tagle, Niemann-Pick C1 disease gene: Homology to mediators of cholesterol homeostasis, Science 277 (1997) 228-231.

[78] S.K. Loftus, J.A. Morris, E.D. Carstea, J.Z. Gu, C. Cummings, A. Brown, J. Ellison, K. Ohne, M.A. Rosenfeld, D.A. Tagle, P.G. Pentchev, W.J. Pavan, Murine model of Niemann-Pick C disease: mutation in a cholesterol homeostasis gene, Science 277 (1997) 232-235.

[79] R.L. Lester, R.C. Dickson, Sphingolipids with inositolphosphate-containing head groups, Adv. Lipid Res. 26 (1993) 253-274.

[80] S.W. Smith, R.L. Lester, Inositol phosphorylceramide, a novel substance and the chief member of a major group of yeast sphingolipids containing a single inositol phosphate, J. Biol. Chem. 249 (1974) 3395-3405.

[81] J.L. Patton, R.L. Lester, The phosphoinositol sphingolipids of Saccharomyces cerevisiae are highly localized in the plasma membrane, J. Bacteriol. 173 (1991) 3101-3108.

[82] P. Hechtberger, E. Zinser, R. Saf, K. Hummel, F. Paltauf, G. Daum, Characterization, quantification and subcellular localization of inositol-containing sphingolipids of the yeast,
Saccharomyces cerevisiae, Eur. J. Biochem. 225 (1994) 641649.

[83] F. Reggiori, E. Canivenc-Gansel, A. Conzelmann, Lipid remodeling leads to the introduction and exchange of defined ceramides on GPI proteins in the ER and Golgi of Saccharomyces cerevisiae, EMBO J. 16 (1997) 3506-3518.

[84] F. Reggiori, A. Conzelmann, Biosynthesis of inositol phosphoceramides and remodeling of glycosylphosphatidylinositol anchors in Saccharomyces cerevisiae are mediated by different enzymes, J. Biol. Chem. 273 (1998) 30550-30559.

[85] C. Linington, M.G. Rumsby, Accessibility of galactosyl ceramides to probe reagents in central nervous system myelin, J. Neurochem. 35 (1980) 983-992.

[86] C.G. Gahmberg, S.-I. Hakomori, External labeling of cell surface galactose and galactosamine in glycolipid and glycoprotein of human erythrocytes, J. Biol. Chem. 248 (1973) 4311-4317.

[87] T.L. Steck, G. Dawson, Topographical distribution of complex carbohydrates in the erythrocyte membrane, J. Biol. Chem. 249 (1974) 2135-2142.

[88] A. Lampio, J. Finne, D. Homer, C.G. Gahmberg, Exposure of the major red-cell glycolipid, globoside, to galactose oxidase, Eur. J. Biochem. 145 (1984) 77-82.

[89] L.J. Macala, H.C. Yohe, In situ accessibility of murine macrophage gangliosides, Glycobiology 5 (1995) 67-75.

[90] H. Miller-Podraza, R.M. Bradley, P.H. Fishman, Biosynthesis and localization of gangliosides in cultured cells, Biochemistry 21 (1982) 3260-3265.

[91] H. Miller-Podraza, P.H. Fishman, Translocation of newly synthesized gangliosides to the cell surface, Biochemistry 21 (1982) 3265-3270.

[92] W.W. Young Jr., M.S. Lutz, W.A. Blackburn, Endogenous glycosphingolipids move to the cell surface at a rate consistent with bulk flow estimates, J. Biol. Chem. 267 (1992) 12011-12015.

[93] W. Stoffel, R. Anderson, J. Stahl, Studies on the asymmetric arrangement of membrane lipid-enveloped virions as a model system, Hoppe-Seyler's Z. Physiol. Chem. 356 (1975) 1123-1129.

[94] W. Stoffel, W. Sorgo, Asymmetry of the lipid-bilayer of Sindbis virus, Chem. Phys. Lipids 17 (1976) 324-335.

[95] T.A. Brasitus, D. Schachter, Lipid dynamics and lipid-protein interactions in the rat enterocyte basolateral and microvillus membranes, Biochemistry 19 (1980) 2763-2769.

[96] C.D. Stubbs, B. Ketterer, R.M. Hicks, The isolation and analysis of the luminal plasma membrane of calf urinary bladder epithelium, Biochim. Biophys. Acta 558 (1979) 5872.

[97] P.W. Wertz, D.T. Downing, R.K. Freinkel, T.N. Traczyk, Sphingolipids of the stratum corneum and lamellar granules of fetal rat epidermis, J. Invest. Dermatol. 83 (1984) 193195.

[98] Y. Takagi, E. Kriehuber, G. Imokawa, P.M. Elias, W.M. Holleran, Beta-glucocerebrosidase activity in mammalian stratum corneum, J. Lipid Res. 40 (1999) 861-869.

[99] D.B. Weinstein, J.B. Marsh, M.C. Glick, L. Warren, Mem- 
branes of animal cells. VI. The glycolipids of the L cell and its surface membrane, J. Biol. Chem. 245 (1970) 3928-3937.

[100] S. Chatterjee, P.O. Kwiterovich Jr., P. Gupta, Y.S. Erozan, C.R. Alving, R.L. Richards, Localization of urinary lactosylceramide in cytoplasmic vesicles of renal tubular cells in homozygous familial hypercholesterolemia, Proc. Natl. Acad. Sci. USA 80 (1983) 1313-1317.

[101] G.R. Matyas, D.J. Morré, Subcellular distribution and biosynthesis of rat liver gangliosides, Biochim. Biophys. Acta 921 (1987) 599-614.

[102] F.W. Symington, W.A. Murray, S.I. Bearman, S.-i. Hakomori, Intracellular localization of lactosylceramide, the major human neutrophil glycosphingolipid, J. Biol. Chem. 262 (1987) 11356-11363.

[103] K. Sakakibara, T. Momoi, T. Uchida, Y. Nagai, Evidence for association of glycosphingolipid with a colchicine-sensitive microtubule-like cytoskeletal structure of cultured cells, Nature 293 (1981) 76-79.

[104] B.K. Gillard, J.P. Heath, L.T. Thurmon, D.M. Marcus, Association of glycosphingolipids with intermediate filaments of human umbilical vein endothelial cells, Exp. Cell Res. 192 (1991) 433-444.

[105] B.K. Gillard, L.T. Thurmon, D.M. Marcus, Association of glycosphingolipids with intermediate filaments of mesenchymal, epithelial, glial, and muscle cells, Cell Motil. Cytoskel. 21 (1992) 255-271.

[106] B.K. Gillard, L.T. Thurmon, D.M. Marcus, Variable subcellular localization of glycosphingolipids, Glycobiology 3 (1993) 57-67.

[107] I.L. van Genderen, G. van Meer, J.W. Slot, H.J. Geuze, W.F. Voorhout, Subcellular localization of Forssman glycolipid in epithelial MDCK cells by immuno-electronmicroscopy after freeze-substitution, J. Cell Biol. 115 (1991) 1009-1019.

[108] E.V. Dyatlovitskaya, A.M. Novikov, N.P. Gorkova, L.D. Bergelson, Gangliosides of hepatoma 27, normal and regenerating rat liver, Eur. J. Biochem. 63 (1976) 357-364.

[109] R.G. Parton, Ultrastructural localization of gangliosides; GM1 is concentrated in caveolae, J. Histochem. Cytochem. 42 (1994) 155-166.

[110] H. Coste, M.B. Martel, R. Got, Topology of glucosylceramide synthesis in Golgi membranes from porcine submaxillary glands, Biochim. Biophys. Acta 858 (1986) 6-12.

[111] S. Sonnino, R. Ghidoni, A. Fiorilli, B. Venerando, G. Tettamanti, Cytosolic gangliosides of rat brain: their fractionation into protein-bound complexes of different ganglioside compositions, J. Neurosci. Res. 12 (1984) 193-204.

[112] V. Chigorno, M. Valsecchi, D. Acquotti, S. Sonnino, G. Tettamanti, Formation of a cytosolic ganglioside-protein complex following administration of photoreactive ganglioside GM1 to human fibroblasts in culture, FEBS Lett. 263 (1990) 329-331.

[113] K.-F. Chan, Y. Liu, Ganglioside-binding proteins in skeletal and cardiac muscle, Glycobiology 1 (1991) 193-203.

[114] H. Higashi, A. Omori, T. Yamagata, Calmodulin, a ganglioside-binding protein. Binding of gangliosides to calmod- ulin in the presence of calcium, J. Biol. Chem. 267 (1992) 9831-9838.

[115] D.E. Warnock, C. Roberts, M.S. Lutz, W.A. Blackburn, W.W. Young Jr., J.U. Baenziger, Determination of plasma membrane lipid mass and composition in cultured Chinese hamster ovary cells using high gradient magnetic affinity chromatography, J. Biol. Chem. 268 (1993) 10145-10153.

[116] G. van Echten-Deckert, A. Klein, T. Linke, T. Heinemann, J. Weisgerber, K. Sandhoff, Turnover of endogenous ceramide in cultured normal and Farber-fibroblasts, J. Lipid Res. 38 (1997) 2569-2579.

[117] M. Chatelut, M. Leruth, K. Harzer, A. Dagan, S. Marchesini, S. Gatt, R. Salvayre, P. Courtoy, T. Levade, Natural ceramide is unable to escape the lysosome, in contrast to a fluorescent analogue, FEBS Lett. 426 (1998) 102-106.

[118] A.H. Merrill Jr., C.C. Sweeley, Sphingolipids: metabolism and cell signalling, in: D. Vance, J.E. Vance (Eds.), Biochemistry of Lipids, Lipoproteins and Membranes, 1996, pp. 309-339.

[119] R.C. Dickson, R.L. Lester, Yeast sphingolipids, Biochim. Biophys. Acta 1426 (1999) 347-357.

[120] J. Rother, G. van Echten, G. Schwarzmann, K. Sandhoff, Biosynthesis of sphingolipids: dihydroceramide and not sphinganine is desaturated by cultured cells, Biochem. Biophys. Res. Commun. 189 (1992) 14-20.

[121] C. Michel, G. van Echten-Deckert, J. Rother, K. Sandhoff, E. Wang, A.H. Merrill Jr., Characterization of ceramide synthesis - a dihydroceramide desaturase introduces the 4,5-trans-double bond of sphingosine at the level of dihydroceramide, J. Biol. Chem. 272 (1997) 22432-22437.

[122] E.C. Mandon, I. Ehses, J. Rother, G. van Echten, K. Sandhoff, Subcellular localization and membrane topology of serine palmitoyltransferase, 3-dehydrosphinganine reductase, and sphinganine $\mathrm{N}$-acyltransferase in mouse liver, J. Biol. Chem. 267 (1992) 11144-11148.

[123] H.S. Overkleeft, G.H. Renkema, J. Neele, P. Vianello, I.O. Hung, A. Strijland, A.M. van der Burg, G.-J. Koomen, U.K. Pandit, J.M.F.G. Aerts, Generation of specific deoxynojirimycin-type inhibitors of the non-lysosomal glucosylceramidase, J. Biol. Chem. 273 (1998) 26522-26527.

[124] J. Koch, S. Gartner, C.M. Li, L.E. Quintern, K. Bernardo, O. Levran, D. Schnabel, R.J. Desnick, E.H. Schuchman, K. Sandhoff, Molecular cloning and characterization of a fulllength complementary DNA encoding human acid ceramidase. Identification of the first molecular lesion causing Farber disease, J. Biol. Chem. 271 (1996) 33110-33115.

[125] C.M. Li, S.B. Hong, G. Kopal, X. He, T. Linke, W.S. Hou, J. Koch, S. Gatt, K. Sandhoff, E.H. Schuchman, Cloning and characterization of the full-length cDNA and genomic sequences encoding murine acid ceramidase, Genomics 50 (1998) 267-274.

[126] T. Kohama, A. Olivera, L. Edsall, M.M. Nagiec, R. Dickson, S. Spiegel, Molecular cloning and functional characterization of murine sphingosine kinase, J. Biol. Chem. 273 (1998) 23722-23728.

[127] M.M. Lanterman, J.D. Saba, Characterization of sphingo- 
sine kinase (SK) activity in Saccharomyces cerevisiae and isolation of SK-deficient mutants, Biochem. J. 332 (1998) $525-531$.

[128] M.M. Nagiec, M. Skrzypek, E.E. Nagiec, R.L. Lester, R.C. Dickson, The LCB4 (YOR171c) and LCB5 (YLR260w) genes of Saccharomyces encode sphingoid long chain base kinases, J. Biol. Chem. 273 (1998) 19437-19442.

[129] R.W. Keenan, Sphingolipid base phosphorylation by cellfree preparations from Tetrahymena pyriformis, Biochim. Biophys. Acta 270 (1972) 383-396.

[130] Y. Banno, M. Kato, A. Hara, Y. Nozawa, Evidence for the presence of multiple forms of Sph kinase in human platelets, Biochem. J. 335 (1998) 301-304.

[131] A. Olivera, T. Kohama, Z. Tu, S. Milstien, S. Spiegel, Purification and characterization of rat kidney sphingosine kinase, J. Biol. Chem. 273 (1998) 12576-12583.

[132] P.P. van Veldhoven, G.P. Mannaerts, Subcellular localization and membrane topology of sphingosine-1-phosphate lyase in rat liver, J. Biol. Chem. 266 (1991) 12502-12507.

[133] J.D. Saba, F. Nara, A. Bielawska, S. Garrett, Y.A. Hannun, The BST1 gene of Saccharomyces cerevisiae is the sphingosine-1-phosphate lyase, J. Biol. Chem. 272 (1997) 26087-26090.

[134] J. Zhou, J.D. Saba, Identification of the first mammalian sphingosine phosphate lyase gene and its functional expression in yeast, Biochem. Biophys. Res. Commun. 242 (1998) $502-507$.

[135] M.S. Skrzypek, M.M. Nagiec, R.L. Lester, R.C. Dickson, Analysis of phosphorylated sphingolipid long-chain bases reveals potential roles in heat stress and growth control in Saccharomyces, J. Bacteriol. 181 (1999) 1134-1140.

[136] P.P. van Veldhoven, G.P. Mannaerts, Sphinganine 1-phosphate metabolism in cultured skin fibroblasts: evidence for the existence of a sphingosine phosphatase, Biochem. J. 299 (1994) 597-601.

[137] C. Mao, M. Wadleigh, G.M. Jenkins, Y.A. Hannun, L.M. Obeid, Identification and characterization of Saccharomyces cerevisiae dihydrosphingosine-1-phosphate phosphatase, J. Biol. Chem. 272 (1997) 28690-28694.

[138] S.M. Mandala, R. Thornton, Z. Tu, M.B. Kurtz, J. Nickels, J. Broach, R. Menzeleev, S. Spiegel, Sphingoid base 1phosphate phosphatase: a key regulator of sphingolipid metabolism and stress response, Proc. Natl. Acad. Sci. USA 95 (1998) 150-155.

[139] R. Jasinska, Q.X. Zhang, C. Pilquil, I. Singh, J. Xu, J. Dewald, D.A. Dillon, L.G. Berthiaume, G.M. Carman, D.W. Waggoner, D.N. Brindley, Lipid phosphate phosphohydrolase-1 degrades exogenous glycerolipid and sphingolipid phosphate esters, Biochem. J. 340 (1999) 677-686.

[140] A.H. Futerman, B. Stieger, A.L. Hubbard, R.E. Pagano, Sphingomyelin synthesis in rat liver occurs predominantly at the cis and medial cisternae of the Golgi apparatus, J. Biol. Chem. 265 (1990) 8650-8657.

[141] D. Jeckel, A. Karrenbauer, R. Birk, R.R. Schmidt, F. Wieland, Sphingomyelin is synthesized in the cis Golgi, FEBS Lett. 261 (1990) 155-157.
[142] D. Jeckel, A. Karrenbauer, K.N.J. Burger, G. van Meer, F. Wieland, Glucosylceramide is synthesized at the cytosolic surface of various Golgi subfractions, J. Cell Biol. 117 (1992) 259-267.

[143] R.D. Klausner, J.G. Donaldson, J. Lippincott-Schwartz, Brefeldin A: Insights into the control of membrane traffic and organelle structure, J. Cell Biol. 116 (1992) 1071-1080.

[144] G. van Meer, W. van 't Hof, Epithelial sphingolipid sorting is insensitive to reorganization of the Golgi by nocodazole, but is abolished by monensin in MDCK cells and by brefeldin A in Caco-2 cells, J. Cell Sci. 104 (1993) 833842.

[145] G. van Echten, H. Iber, H. Stotz, A. Takatsuki, K. Sandhoff, Uncoupling of ganglioside biosynthesis by brefeldin A, Eur. J. Cell Biol. 51 (1990) 135-139.

[146] A. van Helvoort, W. van 't Hof, T. Ritsema, A. Sandra, G. van Meer, Conversion of diacylglycerol to phosphatidylcholine on the basolateral surface of epithelial (Madin-Darby canine kidney) cells. Evidence for the reverse action of a sphingomyelin synthase, J. Biol. Chem. 269 (1994) 17631769.

[147] A. van Helvoort, A.J. Smith, H. Sprong, I. Fritzsche, A.H. Schinkel, P. Borst, G. van Meer, MDR1 P-glycoprotein is a lipid translocase of broad specificity, while MDR3 P-glycoprotein specifically translocates phosphatidylcholine, Cell 87 (1996) 507-517.

[148] A. van Helvoort, W. Stoorvogel, G. van Meer, K.N.J. Burger, Sphingomyelin synthase is absent from endosomes, J. Cell Sci. 110 (1997) 781-788.

[149] M. Koval, A.H. Futerman, R.E. Pagano, K.-J. Kallen, D. Allan, Sphingomyelin synthesis in endosomal compartments?, Trends Cell Biol. 5 (1995) 148-149.

[150] S. Ichikawa, H. Sakiyama, G. Suzuki, K.I.-P.J. Hidari, Y. Hirabayashi, Expression cloning of a cDNA for human ceramide glucosyltransferase that catalyzes the first glycosylation step of glycosphingolipid synthesis, Proc. Natl. Acad. Sci. USA 93 (1996) 4638-4643.

[151] A.H. Futerman, R.E. Pagano, Determination of the intracellular sites and topology of glucosylceramide synthesis in rat liver, Biochem. J. 280 (1991) 295-302.

[152] A. Schweizer, H. Clausen, G. van Meer, H.-P. Hauri, Localization of $O$-glycan initiation, sphingomyelin synthesis, and glucosylceramide synthesis in Vero cells with respect to the endoplasmic reticulum-Golgi intermediate compartment, J. Biol. Chem. 269 (1994) 4035-4041.

[153] H. Lannert, C. Bünning, D. Jeckel, F.T. Wieland, Lactosylceramide is synthesized in the lumen of the Golgi apparatus, FEBS Lett. 342 (1994) 91-96.

[154] T. Nomura, M. Takizawa, J. Aoki, H. Arai, K. Inoue, E. Wakisaka, N. Yoshizuka, G. Imokawa, N. Dohmae, K. Takio, M. Hattori, N. Matsuo, Purification, cDNA cloning, and expression of UDP-Gal: glucosylceramide beta1,4-galactosyltransferase from rat brain, J. Biol. Chem. 273 (1998) 13570-13577.

[155] J. Sorge, C. West, B. Westwood, E. Beutler, Molecular cloning and nucleotide sequence of human glucocerebrosi- 
dase cDNA, Proc. Natl. Acad. Sci. USA 82 (1985) 7289 7293.

[156] A. Makita, N. Taniguchi, Glycosphingolipids, in: H. Wiegandt (Ed.), Glycolipids, Vol. 10, A. Neuberger, L.L.M. van Deenen (Series Eds.), New Comprehensive Biochemistry, 1985, pp. 1-99.

[157] A. Ishii, M. Ohta, Y. Watanabe, K. Matsuda, K. Ishiyama, K. Sakoe, M. Nakamura, J. Inokuchi, Y. Sanai, M. Saito, Expression cloning and functional characterization of human cDNA for ganglioside $\mathrm{G}_{\mathrm{M} 3}$ synthase, J. Biol. Chem. 273 (1998) 31652-31655.

[158] M. Kono, S. Takashima, H. Liu, M. Inoue, N. Kojima, Y.C. Lee, T. Hamamoto, S. Tsuji, Molecular cloning and functional expression of a fifth-type alpha 2,3-sialyltransferase (mST3Gal V: GM3 synthase), Biochem. Biophys. Res. Commun. 253 (1998) 170-175.

[159] S. Fukumoto, H. Miyazaki, G. Goto, T. Urano, K. Furukawa, Expression cloning of mouse cDNA of CMP-NeuAc:lactosylceramide alpha2,3-sialyltransferase, an enzyme that initiates the synthesis of gangliosides, J. Biol. Chem. 274 (1999) 9271-9276.

[160] M.S. Lutz, E. Jaskiewicz, D.S. Darling, K. Furukawa, W.W. Young Jr., Cloned $\beta$ 1,4N-acetylgalactosaminyltransferase synthezises $G_{A 2}$ as well as gangliosides $G_{M 2}$ and $G_{D 2}$. $\mathrm{G}_{\mathrm{M} 3}$ synthesis has priority over $\mathrm{G}_{\mathrm{A} 2}$ synthesis for utilization of lactosylceramide substrate in vivo, J. Biol. Chem. 269 (1994) 29227-29231.

[161] M. Trinchera, R. Ghidoni, Two glycosphingolipid sialyltransferases are localized in different sub-Golgi compartments in rat liver, J. Biol. Chem. 264 (1989) 1576615769.

[162] M. Trinchera, B. Pirovano, R. Ghidoni, Sub-Golgi distribution in rat liver of CMP-NeuAc GM3- and CMP-NeuAc:GT1bo2 $\rightarrow 8$ sialyltransferases and comparison with the distribution of the other glycosyltransferase activities involved in ganglioside biosynthesis, J. Biol. Chem. 265 (1990) 18242-18247.

[163] H. Iber, G. van Echten, K. Sandhoff, Fractionation of primary cultured cerebellar neurons: Distribution of sialyltransferases involved in ganglioside biosynthesis, J. Neurochem. 58 (1992) 1533-1537.

[164] H. Lannert, K. Gorgas, I. Meißner, F.T. Wieland, D. Jeckel, Functional organization of the Golgi apparatus in glycosphingolipid biosynthesis. Lactosylceramide and subsequent glycosphingolipids are formed in the lumen of the late Golgi, J. Biol. Chem. 273 (1998) 2939-2946.

[165] W.W. Young Jr., M.S. Lutz, S.E. Mills, S. Lechler-Osborn, Use of brefeldin A to define sites of glycosphingolipid synthesis: GA2/GM2/GD2 synthase is trans to the brefeldin A block, Proc. Natl. Acad. Sci. USA 87 (1990) 6838-6842.

[166] A.L. Sherwood, E.H. Holmes, Brefeldin A induced inhibition of de novo globo- and neolacto-series glycolipid core chain biosynthesis in human cells, J. Biol. Chem. 267 (1992) 25328-25336.

[167] V.M. Rosales Fritz, H.J. Maccioni, Effects of brefeldin A on synthesis and intracellular transport of ganglioside GT3 by chick embryo retina cells, J. Neurochem. 65 (1995) 1859-1864.

[168] H. Miller-Prodraza, P.H. Fishman, Effect of drugs and temperature on biosynthesis and transport of glycosphingolipids in cultured neurotumor cells, Biochim. Biophys. Acta 804 (1984) 44-51.

[169] M. Saito, M. Saito, A. Rosenberg, Action of monensin, a monovalent cationophore, on cultured human fibroblasts: Evidence that it induces high cellular accumulation of glucosyl- and lactosylceramide (gluco- and lactocerebroside), Biochemistry 23 (1984) 1043-1046.

[170] M. Saito, M. Saito, A. Rosenberg, Influence of monovalent cation transport on anabolism of glycosphingolipids in cultured human fibroblasts, Biochemistry 24 (1985) 3054 3059.

[171] M.V. Hogan, M. Saito, A. Rosenberg, Influence of monensin on ganglioside anabolism and neurite stability in cultured chick neurons, J. Neurosci. Res. 20 (1998) 390-394.

[172] C.M. Gordon, K.O. Lloyd, Endocytosis and recycling of gangliosides in a human melanoma cell line: inhibitory effect of brefeldin A and monensin, Arch. Biochem. Biophys. 315 (1994) 339-344.

[173] H.J. Maccioni, J.L. Daniotti, J.A. Martina, Organization of ganglioside synthesis in the Golgi apparatus, Biochim. Biophys. Acta 1437 (1999) 101-118.

[174] E. Jaskiewicz, G.F. Zhu, D.J. Taatjes, D.S. Darling, G.E. Zwanzig, W.W. Young Jr., Cloned $\beta 1,4 N$-acetylgalactosaminyltransferase: subcellular localization and formation of disulfide bonded species, Glycoconjug. J. 13 (1996) 213-223.

[175] W.W. Young Jr., M.L. Allende, E. Jaskiewicz, Reevaluating the effect of brefeldin A (BFA) on ganglioside synthesis: the location of GM2 synthase cannot be deduced from the inhibition of GM2 synthesis by BFA, Glycobiology 9 (1999) 689-695.

[176] S. Schulte, W. Stoffel, Ceramide UDPgalactosyltransferase from myelinating rat brain: Purification, cloning, and expression, Proc. Natl. Acad. Sci. USA 90 (1993) 1026510269.

[177] N. Stahl, H. Jurevics, P. Morell, K. Suzuki, B. Popko, Isolation, characterization, and expression of cDNA clones that encode rat UDP-galactose:ceramide galactosyltransferase, J. Neurosci. Res. 38 (1994) 234-242.

[178] A. Bosio, E. Binczek, M.M. Le Beau, A.A. Fernald, W. Stoffel, The human gene CGT encoding the UDP-galactose ceramide galactosyl transferase (cerebroside synthase): cloning, characterization, and assignment to human chromosome 4, band q26, Genomics 34 (1996) 69-75.

[179] T. Coetzee, X. Li, N. Fujita, J. Marcus, K. Suzuki, U. Francke, B. Popko, Molecular cloning, chromosomal mapping, and characterization of the mouse UDP-galactose: ceramide galactosyltransferase gene, Genomics 35 (1996) 215-222.

[180] H. Sprong, B. Kruithof, R. Leijendekker, J.W. Slot, G. van Meer, P. van der Sluijs, UDP-galactose:ceramide galactosyltransferase is a class I integral membrane protein of the 
endoplasmic reticulum, J. Biol. Chem. 273 (1998) 2588025888.

[181] P. Morell, N.S. Radin, Synthesis of cerebroside by brain from uridine diphosphate galactose and ceramide containing hydroxy fatty acid, Biochemistry 8 (1969) 506-512.

[182] P. van der Bijl, G.J. Strous, M. Lopes-Cardozo, J. ThomasOates, G. van Meer, Synthesis of non-hydroxy-galactosylceramides and galactosyldiglycerides by hydroxy-ceramide galactosyltransferase, Biochem. J. 317 (1996) 589-597.

[183] G. Tennekoon, M. Zaruba, J. Wolinsky, Topography of cerebroside sulfotransferase in Golgi-enriched vesicles from rat brain, J. Cell Biol. 97 (1983) 1107-1112.

[184] K. Honke, M. Tsuda, Y. Hirahara, A. Ishii, A. Makita, Y. Wada, Molecular cloning and expression of cDNA encoding human 3'-phosphoadenylylsulfate:galactosylceramide 3'-sulfotransferase, J. Biol. Chem. 272 (1997) $4864-4868$.

[185] M.M. Nagiec, E.E. Nagiec, J.A. Baltisberger, G.B. Wells, R.L. Lester, R.C. Dickson, Sphingolipid synthesis as a target for antifungal drugs. Complementation of the inositol phosphorylceramide synthase defect in a mutant strain of Saccharomyces cerevisiae by the AUR1 gene, J. Biol. Chem. 272 (1997) 9809-9817.

[186] M. Kuroda, T. Hashida-Okado, R. Yasumoto, K. Gomi, I. Kato, K. Takesako, An aureobasidin A resistance gene isolated from Aspergillus is a homolog of yeast AUR1, a gene responsible for inositol phosphorylceramide (IPC) synthase activity, Mol. Gen. Genet. 261 (1999) 290-296.

[187] T.J. Beeler, D. Fu, J. Rivera, E. Monaghan, K. Gable, T.M. Dunn, SUR1 (CSG1/BCL21), a gene necessary for growth of Saccharomyces cerevisiae in the presence of high $\mathrm{Ca}^{2+}$ concentrations at 37 degrees $\mathrm{C}$, is required for mannosylation of inositolphosphorylceramide, Mol. Gen. Genet. 255 (1997) 570-579.

[188] N. Dean, Y.B. Zhang, J.B. Poster, The VRG4 gene is required for GDP-mannose transport into the lumen of the Golgi in the yeast, Saccharomyces cerevisiae, J. Biol. Chem. 272 (1997) 31908-31914.

[189] R.C. Dickson, E.E. Nagiec, G.B. Wells, M.M. Nagiec, R.L. Lester, Synthesis of mannose-(inositol-P) $)_{2}$-ceramide, the major sphingolipid in Saccharomyces cerevisiae, requires the IPT1 (YDR072c) gene, J. Biol. Chem. 272 (1997) 29620-29625.

[190] E.D. Sheets, G.M. Lee, R. Simson, K. Jacobson, Transient confinement of a glycosylphosphatidylinositol-anchored protein in the plasma membrane, Biochemistry 36 (1997) 12449-12458.

[191] D.A. Brown, E. London, Structure of detergent-resistant membrane domains: does phase separation occur in biological membranes?, Biochem. Biophys. Res. Commun. 240 (1997) 1-7.

[192] D.A. Brown, Sphingolipid organization in biomembranes: what physical studies of model membranes reveal, J. Cell Sci. 111 (1998) 1-9.

[193] D.A. Brown, J.K. Rose, Sorting of GPI-anchored proteins to glycolipid-enriched membrane subdomains during transport to the apical cell surface, Cell 68 (1992) 533-544.
[194] K.A. Melkonian, A.G. Ostermeyer, J.Z. Chen, M.G. Roth, D.A. Brown, Role of lipid modifications in targeting proteins to detergent-resistant membrane rafts. Many raft proteins are acylated, while few are prenylated, J. Biol. Chem. 274 (1999) 3910-3917.

[195] J.E. Skibbens, M.G. Roth, K.S. Matlin, Differential extractability of influenza virus hemagglutinin during intracellular transport in polarized epithelial cells and non-polar fibroblasts, J. Cell Biol. 108 (1989) 821-832.

[196] M. Alfalah, R. Jacob, U. Preuss, K.P. Zimmer, H. Naim, H.Y. Naim, O-linked glycans mediate apical sorting of human intestinal sucrase-isomaltase through association with lipid rafts, Curr. Biol. 9 (1999) 593-596.

[197] M. Frank, M.E. van der Haar, N. Schaeren-Wiemers, M.E. Schwab, rMAL is a glycosphingolipid-associated protein of myelin and apical membranes of epithelial cells in kidney and stomach, J. Neurosci. 18 (1998) 4901-4913.

[198] K.H. Cheong, D. Zacchetti, E.E. Schneeberger, K. Simons, VIP17/MAL, a lipid raft-associated protein, is involved in apical transport in MDCK cells, Proc. Natl. Acad. Sci. USA 96 (1999) 6241-6248.

[199] K. Bruckner, J. Pablo Labrador, P. Scheiffele, A. Herb, P.H. Seeburg, R. Klein, EphrinB ligands recruit GRIP family PDZ adaptor proteins into raft membrane microdomains, Neuron 22 (1999) 511-524.

[200] R.G.W. Anderson, Plasmalemmal caveolae and GPI-anchored membrane proteins, Curr. Opin. Cell Biol. 5 (1993) 647-652.

[201] R.G.W. Anderson, The caveolae membrane system, Annu. Rev. Biochem. 67 (1998) 199-225.

[202] A.M. Fra, E. Williamson, K. Simons, R.G. Parton, Detergent-insoluble glycolipid microdomains in lymphocytes in the absence of caveolae, J. Biol. Chem. 269 (1994) 3074530748.

[203] A. Gorodinsky, D.A. Harris, Glycolipid-anchored proteins in neuroblastoma cells form detergent-resistant complexes without caveolin, J. Cell Biol. 129 (1995) 619-627.

[204] C. Butor, E.H.K. Stelzer, A. Sonnenberg, J. Davoust, Apical and basal Forssman antigen in MDCK II cells: a morphological and quantitative study, Eur. J. Cell Biol. 56 (1991) 269-285.

[205] S. Mayor, K.G. Rothberg, F.R. Maxfield, Sequestration of GPI-anchored proteins in caveolae triggered by cross-linking, Science 264 (1994) 1948-1951.

[206] S. Mayor, F.R. Maxfield, Insolubility and redistribution of GPI-anchored proteins at the cell surface after detergent treatment, Mol. Biol. Cell 6 (1995) 929-944.

[207] T. Fujimoto, GPI-anchored proteins, glycosphingolipids, and sphingomyelin are sequestered to caveolae only after crosslinking, J. Histochem. Cytochem. 44 (1996) 929-941.

[208] T. Friedrichson, T.V. Kurzchalia, Microdomains of GPIanchored proteins in living cells revealed by crosslinking, Nature 394 (1998) 802-805.

[209] R. Varma, S. Mayor, GPI-anchored proteins are organized in submicron domains at the cell surface, Nature 394 (1998) 798-801. 
[210] A. Pralle, M. Prummer, E.L. Florin, E.H.K. Stelzer, J.K.H. Horber, Three-dimensional high-resolution particle tracking for optical tweezers by forward scattered light, Microsc. Res. Tech. 44 (1999) 378-386.

[211] T. Harder, P. Scheiffele, P. Verkade, K. Simons, Lipid domain structure of the plasma membrane revealed by patching of membrane components, J. Cell Biol. 141 (1998) 929 942.

[212] C. Montixi, C. Langlet, A.M. Bernard, J. Thimonier, C. Dubois, M.A. Wurbel, J.P. Chauvin, M. Pierres, H.T. $\mathrm{He}$, Engagement of $\mathrm{T}$ cell receptor triggers its recruitment to low-density detergent-insoluble membrane domains, EMBO J. 17 (1998) 5334-5348.

[213] T. Harder, K. Simons, Clusters of glycolipid and glycosylphosphatidylinositol-anchored proteins in lymphoid cells: accumulation of actin regulated by local tyrosine phosphorylation, Eur. J. Immunol. 29 (1999) 556-562.

[214] V. Horejs, K. Drbal, M. Cebecauer, J. Cern, T. Brdicka, P. Angelisov, H. Stockinger, GPI-microdomains: a role in signalling via immunoreceptors, Immunol. Today 20 (1999) 356-361.

[215] A.K. Kenworthy, M. Edidin, Distribution of a glycosylphosphatidylinositol-anchored protein at the apical surface of MDCK cells examined at a resolution of $<100 \AA$ using imaging fluorescence resonance energy transfer, J. Cell Biol. 142 (1998) 69-84.

[216] B.R. Ganong, R.M. Bell, Transmembrane movement of phosphatidylglycerol and diacylglycerol sulfhydryl analogues, Biochemistry 23 (1984) 4977-4983.

[217] J. Bai, R.E. Pagano, Measurement of spontaneous transfer and transbilayer movement of BODIPY-labeled lipids in lipid vesicles, Biochemistry 36 (1997) 8840-8848.

[218] M. Bodzioch, E. Orso, J. Klucken, T. Langmann, A. Bottcher, W. Diederich, W. Drobnik, S. Barlage, C. Buchler, M. Porsch-Ozcurumez, W.E. Kaminski, H.W. Hahmann, K. Oette, G. Rothe, C. Aslanidis, K.J. Lackner, G. Schmitz, The gene encoding ATP-binding cassette transporter 1 is mutated in Tangier disease, Nature Genet. 22 (1999) 347-351.

[219] A. Brooks-Wilson, M. Marcil, S.M. Clee, L.-H. Zhang, K. Roomp, M. van Dam, L. Yu, C. Brewer, J.A. Collins, H.O.F. Molhuizen, O. Loubser, B.F.F. Ouelette, K. Fichter, K.J. Ashbourne-Excoffon, C.W. Sensen, S. Scherer, S. Mott, M. Denis, D. Martindale, J. Frohlich, K. Morgan, B. Koop, S. Pimstone, J.J.P. Kastelein, J. Genest Jr., M.R. Hayden, Mutations in $A B C 1$ in Tangier disease and familial high-density lipoprotein deficiency, Nature Genet. 22 (1999) 336-345.

[220] T. Langmann, J. Klucken, M. Reil, G. Liebisch, M.F. Luciani, G. Chimini, W.E. Kaminski, G. Schmitz, Molecular cloning of the human ATP-binding cassette transporter 1 (hABC1): evidence for sterol-dependent regulation in macrophages, Biochem. Biophys. Res. Commun. 257 (1999) 2933.

[221] S. Rust, M. Rosier, H. Funke, J. Real, Z. Amoura, J.C. Piette, J.F. Deleuze, H.B. Brewer, N. Duverger, P. Denefle,
G. Assmann, Tangier disease is caused by mutations in the gene encoding ATP-binding cassette transporter 1, Nature Genet. 22 (1999) 352-355.

[222] N.G. Lipsky, R.E. Pagano, Sphingolipid metabolism in cultured fibroblasts: Microscopic and biochemical studies employing a fluorescent ceramide analogue, Proc. Natl. Acad. Sci. USA 80 (1983) 2608-2612.

[223] N.G. Lipsky, R.E. Pagano, Intracellular translocation of fluorescent sphingolipids in cultured fibroblasts: Endogenously synthesized sphingomyelin and glucocerebroside analogues pass through the Golgi apparatus en route to the plasma membrane, J. Cell Biol. 100 (1985) 27-34.

[224] G. van Meer, E.H.K. Stelzer, R.W. Wijnaendts-van Resandt, K. Simons, Sorting of sphingolipids in epithelial (Madin-Darby canine kidney) cells, J. Cell Biol. 105 (1987) 1623-1635.

[225] J.B. Helms, A. Karrenbauer, K.W.A. Wirtz, J.E. Rothman, F.T. Wieland, Reconstitution of steps in the constitutive secretory pathway in permeabilized cells. Secretion of glycosylated tripeptide and truncated sphingomyelin, J. Biol. Chem. 265 (1990) 20027-20032.

[226] A. Karrenbauer, D. Jeckel, W. Just, R. Birk, R.R. Schmidt, J.E. Rothman, F.T. Wieland, The rate of bulk flow from the Golgi to the plasma membrane, Cell 63 (1990) 259-267.

[227] P. van der Bijl, M. Lopes-Cardozo, G. van Meer, Sorting of newly synthesized galactosphingolipids to the two surface domains of epithelial cells, J. Cell Biol. 132 (1996) 813821.

[228] G. van Echten, R. Birk, G. Brenner-Weiss, R.R. Schmidt, K. Sandhoff, Modulation of sphingolipid biosynthesis in primary cultured neurons by long chain bases, J. Biol. Chem. 265 (1990) 9333-9339.

[229] K.N.J. Burger, P. van der Bijl, G. van Meer, Topology of sphingolipid galactosyltransferases in ER and Golgi: Transbilayer movement of monohexosyl sphingolipids is required for higher glycosphingolipid biosynthesis, J. Cell Biol. 133 (1996) 15-28.

[230] P.F. Devaux, A. Zachowski, Maintenance and consequences of membrane phospholipid asymmetry, Chem. Phys. Lipids 73 (1994) 107-120.

[231] T. Pomorski, P. Müller, B. Zimmermann, K. Burger, P.F. Devaux, A. Herrmann, Transbilayer movement of fluorescent and spin-labeled phospholipids in the plasma membrane of human fibroblasts: a quantitative approach, J. Cell Sci. 109 (1996) 687-698.

[232] T. Pomorski, A. Herrmann, P. Müller, G. van Meer, K. Burger, Protein-mediated inward translocation of phospholipids occurs in both the apical and basolateral plasma membrane domains of epithelial cells, Biochemistry 38 (1999) 142-150.

[233] M. Koval, R.E. Pagano, Lipid recycling between the plasma membrane and intracellular compartments: Transport and metabolism of fluorescent sphingomyelin analogues in cultured fibroblasts, J. Cell Biol. 108 (1989) 2169-2181.

[234] M. Koval, R.E. Pagano, Sorting of an internalized plasma 
membrane lipid between recycling and degradative pathways in normal and Niemann-Pick, type A fibroblasts, J. Cell Biol. 111 (1990) 429-442.

[235] J.W. Kok, T. Babia, D. Hoekstra, Sorting of sphingolipids in the endocytic pathway of HT29 cells, J. Cell Biol. 114 (1991) 231-239.

[236] S. Mayor, J.F. Presley, F.R. Maxfield, Sorting of membrane components from endosomes and subsequent recycling to the cell surface occurs by a bulk flow process, J. Cell Biol. 121 (1993) 1257-1269.

[237] J.F. Presley, S. Mayor, K.W. Dunn, L.S. Johnson, T.E. McGraw, F.R. Maxfield, The End2 mutation in CHO cells slows the exit of transferrin receptors from the recycling compartment but bulk membrane recycling is unaffected, J. Cell Biol. 122 (1993) 1231-1241.

[238] O.C. Martin, R.E. Pagano, Internalization and sorting of a fluorescent analogue of glucosylceramide to the Golgi apparatus of human skin fibroblasts: utilization of endocytic and nonendocytic transport mechanisms, J. Cell Biol. 125 (1994) 769-781.

[239] S.C.D. van IJzendoorn, M.M.P. Zegers, J.W. Kok, D. Hoekstra, Segregation of glucosylceramide and sphingomyelin occurs in the apical to basolateral transcytotic route in HepG2 cells, J. Cell Biol. 137 (1997) 347-357.

[240] S.C.D. van IJzendoorn, D. Hoekstra, (Glyco)sphingolipids are sorted in sub-apical compartments in HepG2 cells: A role for non-Golgi-related intracellular sites in the polarized distribution of (glyco)sphingolipids, J. Cell Biol. 142 (1998) 683-696.

[241] Q. Zhou, J. Zhao, J.G. Stout, R.A. Luhm, T. Wiedmer, P.J. Sims, Molecular cloning of human plasma membrane phospholipid scramblase. A protein mediating transbilayer movement of plasma membrane phospholipids, J. Biol. Chem. 272 (1997) 18240-18244.

[242] Q.S. Zhou, P.J. Sims, T. Wiedmer, Identity of a conserved motif in phospholipid scramblase that is required for $\mathrm{Ca}^{2+}$. accelerated transbilayer movement of membrane phospholipids, Biochemistry 37 (1998) 2356-2360.

[243] E.F. Smeets, P. Comfurius, E.M. Bevers, R.F. Zwaal, Calcium-induced transbilayer scrambling of fluorescent phospholipid analogs in platelets and erythrocytes, Biochim. Biophys. Acta 1195 (1994) 281-286.

[244] P. Gaffet, N. Bettache, A. Bienvenüe, Transverse redistribution of phospholipids during human platelet activation: Evidence for a vectorial outflux specific to aminophospholipids, Biochemistry 34 (1995) 6762-6769.

[245] A. Herrmann, A. Zachowski, P.F. Devaux, Protein-mediated phospholipid translocation in the endoplasmic reticulum with a low lipid specificity, Biochemistry 29 (1990) 2023-2027.

[246] X. Buton, G. Morrot, P. Fellmann, M. Seigneuret, Ultrafast glycerophospholipid-selective transbilayer motion mediated by a protein in the endoplasmic reticulum membrane, J. Biol. Chem. 271 (1996) 6651-6657.

[247] R.J. Raggers, A. van Helvoort, R. Evers, G. van Meer, The human multidrug resistance protein MRP1 translocates sphingolipid analogs across the plasma membrane, J. Cell Sci. 112 (1999) 415-422.

[248] Y. Lavie, H.T. Cao, S.L. Bursten, A.E. Giuliano, M.C. Cabot, Accumulation of glucosylceramides in multidrug-resistant cancer cells, J. Biol. Chem. 271 (1996) 19530-19536.

[249] Y. Lavie, H.T. Cao, A. Volner, A. Lucci, T.Y. Han, V. Geffen, A.E. Giuliano, M.C. Cabot, Agents that reverse multidrug resistance, tamoxifen, verapamil, and cyclosporin A, block glycosphingolipid metabolism by inhibiting ceramide glycosylation in human cancer cells, J. Biol. Chem. 272 (1997) 1682-1687.

[250] J.W. Kok, S. Eskelinen, K. Hoekstra, D. Hoekstra, Salvage of glucosylceramide by recycling after internalization along the pathway of receptor-mediated endocytosis, Proc. Natl. Acad. Sci. USA 86 (1989) 9896-9900.

[251] J.W. Kok, K. Hoekstra, S. Eskelinen, D. Hoekstra, Recycling pathways of glucosylceramide in BHK cells: distinct involvement of early and late endosomes, J. Cell Sci. 103 (1992) 1139-1152.

[252] I. van Genderen, G. van Meer, Differential targeting of glucosylceramide and galactosylceramide analogues after synthesis but not during transcytosis in Madin-Darby canine kidney cells, J. Cell Biol. 131 (1995) 645-654.

[253] K.-J. Kallen, P. Quinn, D. Allan, Effects of brefeldin A on sphingomyelin transport and lipid synthesis in BHK21 cells, Biochem. J. 289 (1993) 307-312.

[254] K.-J. Kallen, P. Quinn, D. Allan, Monensin inhibits synthesis of plasma membrane sphingomyelin by blocking transport of ceramide through the Golgi: evidence for two sites of sphingomyelin synthesis in BHK cells, Biochim. Biophys. Acta 1166 (1993) 305-308.

[255] D.E. Warnock, M.S. Lutz, W.A. Blackburn, W.W. Young Jr., J.U. Baenziger, Transport of newly synthesized glucosylceramide to the plasma membrane by a non-Golgi pathway, Proc. Natl. Acad. Sci. USA 91 (1994) 2708-2712.

[256] E. Fries, I. Lindström, The effects of low temperatures on intracellular transport of newly synthesized albumin and haptoglobin in rat hepatocytes, Biochem. J. 237 (1986) 33-39.

[257] T. Kobayashi, R.E. Pagano, Lipid transport during mitosis. Alternative pathways for delivery of newly synthesized lipids to the cell surface, J. Biol. Chem. 264 (1989) 5966-5973.

[258] P. Hechtberger, G. Daum, Intracellular transport of inositol-containing sphingolipids in the yeast, Saccharomyces cerevisiae, FEBS Lett. 367 (1995) 201-204.

[259] T.H. Söllner, J.E. Rothman, Molecular machinery mediating vesicle budding, docking and fusion, Experientia 52 (1996) 1021-1025.

[260] H.R.B. Pelham, SNAREs and the secretory pathway. Lessons from yeast, Exp. Cell Res. 247 (1999) 1-8.

[261] G. van Meer, Lipid traffic in animal cells, Annu. Rev. Cell Biol. 5 (1989) 247-275.

[262] F. Lafont, P. Verkade, T. Galli, C. Wimmer, D. Louvard, K. Simons, Raft association of SNAP receptors acting in apical trafficking in Madin-Darby canine kidney cells, Proc. Natl. Acad. Sci. USA 96 (1999) 3734-3738. 
[263] R.W. Mays, K.A. Siemers, B.A. Fritz, A.W. Lowe, G. van Meer, W.J. Nelson, Hierarchy of mechanisms involved in generating $\mathrm{Na} / \mathrm{K}$-ATPase polarity in MDCK epithelial cells, J. Cell Biol. 130 (1995) 1105-1115.

[264] A. Horvath, C. Sütterlin, U. Manning-Krieg, N.R. Movva, H. Riezman, Ceramide synthesis enhances transport of GPI-anchored proteins to the Golgi apparatus in yeast, EMBO J. 13 (1994) 3687-3695.

[265] E. Kübler, H.G. Dohlman, M.P. Lisanti, Identification of Triton X-100 insoluble membrane domains in the yeast Saccharomyces cerevisiae. Lipid requirements for targeting of heterotrimeric G-protein subunits, J. Biol. Chem. 271 (1996) 32975-32980.

[266] P. Keller, K. Simons, Cholesterol is required for surface transport of influenza virus hemagglutinin, J. Cell Biol. 140 (1998) 1357-1367.

[267] D.A. Brown, E. London, Structure and origin of ordered lipid domains in biological membranes, J. Membr. Biol. 164 (1998) 103-114.

[268] A. Chattopadhyay, E. London, Parallax method for direct measurement of membrane penetration depth utilizing fluorescence quenching by spin-labeled phospholipids, Biochemistry 26 (1987) 39-45.

[269] P. Cupers, A. Veithen, A. Kiss, P. Baudhuin, P.J. Courtoy, Clathrin polymerization is not required for bulk-phase endocytosis in rat fetal fibroblasts, J. Cell Biol. 127 (1994) 725-735.

[270] A.A. Lindberg, J.E. Brown, N. Strömberg, M. WestlingRyd, J.E. Schultz, K.-A. Karlsson, Identification of the carbohydrate receptor for Shiga toxin produced by Shigella dysenteriae type 1, J. Biol. Chem. 262 (1987) 1779-1785.

[271] P.A. Orlandi, P.K. Curran, P.H. Fishman, Brefeldin A blocks the response of cultured cells to cholera toxin, J. Biol. Chem. 268 (1993) 12010-12016.

[272] K. Sandvig, M. Ryd, Ø. Garred, E. Schweda, P.K. Holm, B. Van Deurs, Retrograde transport from the Golgi complex to the ER of both Shiga toxin and the nontoxic Shiga B-fragment is regulated by butyric acid and cAMP, J. Cell Biol. 126 (1994) 53-64.

[273] F. Mallard, C. Antony, D. Tenza, J. Salamero, B. Goud, L. Johannes, Direct pathway from early/recycling endosomes to the Golgi apparatus revealed through the study of Shiga toxin B-fragment transport, J. Cell Biol. 143 (1998) 973990.

[274] P.A. Orlandi, P.H. Fishman, Filipin-dependent inhibition of cholera toxin: evidence for toxin internalization and activation through caveolae-like domains, J. Cell Biol. 141 (1998) 905-915.

[275] A.A. Wolf, M.G. Jobling, S. Wimer-Mackin, M. FergusonMaltzman, J.L. Madara, R.K. Holmes, W.I. Lencer, Ganglioside structure dictates signal transduction by cholera toxin and association with caveolae-like membrane domains in polarized epithelia, J. Cell Biol. 141 (1998) 917927.

[276] W. Cieplak Jr., R.J. Messer, M.E. Konkel, C.C. Grant, Role of a potential endoplasmic reticulum retention se- quence (RDEL) and the Golgi complex in the cytotoxic activity of Escherichia coli heat-labile enterotoxin, Mol. Microbiol. 16 (1995) 789-800.

[277] W.I. Lencer, C. Constable, S. Moe, M.G. Jobling, H.M. Webb, S. Ruston, J.L. Madara, T.R. Hirst, R.K. Holmes, Targeting of cholera toxin and Escherichia coli heat labile toxin in polarized epithelia: Role of $\mathrm{COOH}$-terminal KDEL, J. Cell Biol. 131 (1995) 951-962.

[278] I.V. Majoul, P.I. Bastiaens, H.D. Söling, Transport of an external Lys-Asp-Glu-Leu (KDEL) protein from the plasma membrane to the endoplasmic reticulum: studies with cholera toxin in Vero cells, J. Cell Biol. 133 (1996) 777-789.

[279] I. Majoul, K. Sohn, F.T. Wieland, R. Pepperkok, M. Pizza, J. Hillemann, H.D. Söling, KDEL receptor (Erd2p)-mediated retrograde transport of the cholera toxin A subunit from the Golgi involves COPI, p23, and the $\mathrm{COOH}$ terminus of Erd2p, J. Cell Biol. 143 (1998) 601-612.

[280] G. Van Echten, K. Sandhoff, Modulation of ganglioside biosynthesis in primary cultured neurons, J. Neurochem. 52 (1989) 207-214.

[281] B.K. Gillard, R.G. Clement, D.M. Marcus, Variations among cell lines in the synthesis of sphingolipids in de novo and recycling pathways, Glycobiology 8 (1998) 885 890.

[282] A. Slomiany, E. Grzelinska, C. Kasinathan, K.-i. Yamaki, D. Palecz, B.A. Slomiany, B.L. Slomiany, Biogenesis of endoplasmic reticulum transport vesicles transferring gastric apomucin from ER to Golgi, Exp. Cell Res. 201 (1992) 321-329.

[283] P. Moreau, C. Cassagne, T.W. Keenan, D.J. Morré, Ceramide excluded from cell-free vesicular lipid transfer from endoplasmic reticulum to Golgi apparatus - Evidence for lipid sorting, Biochim. Biophys. Acta 1146 (1993) 9-16.

[284] R.N. Collins, G. Warren, Sphingolipid transport in mitotic HeLa cells, J. Biol. Chem. 267 (1992) 24906-24911.

[285] C. Featherstone, Coming to grips with the Golgi, Science 282 (1998) 2172-2174.

[286] J.W. Kok, T. Babia, K. Klappe, G. Egea, D. Hoekstra, Ceramide transport from endoplasmic reticulum to Golgi apparatus is not vesicle-mediated, Biochem. J. 333 (1998) 779-786.

[287] M. Fukasawa, M. Nishijima, K. Hanada, Genetic evidence for ATP-dependent endoplasmic reticulum-to-Golgi apparatus trafficking of ceramide for sphingomyelin synthesis in Chinese hamster ovary cells, J. Cell Biol. 144 (1999) 673685.

[288] M.S. Ladinsky, D.N. Mastronarde, J.R. McIntosh, K.E. Howell, L.A. Staehelin, Golgi structure in three dimensions: functional insights from the normal rat kidney cell, J. Cell Biol. 144 (1999) 1135-1149.

[289] A. Puoti, C. Desponds, A. Conzelmann, Biosynthesis of mannosylinositolphosphoceramide in Saccharomyces cerevisiae is dependent on genes controlling the flow of secretory vesicles from the endoplasmic reticulum to the Golgi, J. Cell Biol. 113 (1991) 515-525.

[290] N.B. Cole, J. Ellenberg, J. Song, D. DiEuliis, J. Lippincott- 
Schwartz, Retrograde transport of Golgi-localized proteins to the ER, J. Cell Biol. 140 (1998) 1-15.

[291] J. Lippincott-Schwartz, N. Cole, J. Presley, Unravelling Golgi membrane traffic with green fluorescent protein chimeras, Trends Cell Biol. 8 (1998) 16-20.

[292] M.C. Phillips, W.J. Johnson, G.H. Rothblat, Mechanism and consequences of cellular cholesterol exchange and transfer, Biochim. Biophys. Acta 906 (1987) 223-276.

[293] R.E. Brown, Spontaneous lipid transfer between organized lipid assemblies, Biochim. Biophys. Acta 1113 (1992) 375389.

[294] A. Abe, K. Yamada, T. Sasaki, A protein purified from pig brain accelerates the intermembranous translocation of mono- and dihexosylceramides, but not the translocation of phospholipids, Biochem. Biophys. Res. Commun. 104 (1982) 1386-1393.

[295] R.J. Metz, N.S. Radin, Purification and properties of a cerebroside transfer protein, J. Biol. Chem. 257 (1982) 12901-12907.

[296] X. Lin, P. Mattjus, H.M. Pike, A.J. Windebank, R.E. Brown, Cloning and expression of glycolipid transfer protein from bovine and porcine brain, J. Biol. Chem. 275 (2000) 5104-5110.
[297] K. Sandhoff, T. Kolter, Topology of glycosphingolipid degradation, Trends Cell Biol. 6 (1996) 98-103.

[298] E.V. Dyatlovitskaya, N.G. Timofeeva, E.F. Yakimenko, L.I. Barsukov, G.I. Muzya, L.D. Bergelson, A sphingomyelin transfer protein in rat tumors and fetal liver, Eur. J. Biochem. 123 (1982) 311-315.

[299] K.J. de Vries, A.A.J. Heinrichs, E. Cunningham, F. Brunink, J. Westerman, P.J. Somerharju, S. Cockcroft, K.W.A. Wirtz, G.T. Snoek, An isoform of the phosphatidylinositoltransfer protein transfers sphingomyelin and is associated with the Golgi system, Biochem. J. 310 (1995) 643-649.

[300] T. Yamashita, R. Wada, T. Sasaki, C. Deng, U. Bierfreund, K. Sandhoff, R.L. Proia, A vital role for glycosphingolipid synthesis during development and differentiation, Proc. Natl. Acad. Sci. USA 96 (1999) 9142-9147.

[301] A. Rietveld, S. Neutz, K. Simons, S. Eaton, Association of sterol- and glycosylphosphatidylinositol-linked proteins with Drosophila raft lipid microdomains, J. Biol. Chem. 274 (1999) 12049-12054.

[302] J. Scheel, J. Srinivasan, U. Honnert, A. Henske, T. Kurzchalia, Involvement of caveolin-1 in meiotic cell-cycle progression in Caenorhabditis elegans, Nature Cell Biol. 1 (1999) 127-129. 